ACCEPTED MANUSCRIPT

\title{
Investigation of water microchannel boiling flow regimes using electrical sensing elements along a single microchannel
}

To cite this article before publication: Mohammadmahdi Talebi et al 2019 Meas. Sci. Technol. in press https://doi.org/10.1088/1361-6501/ab38f6

\section{Manuscript version: Accepted Manuscript}

Accepted Manuscript is "the version of the article accepted for publication including all changes made as a result of the peer review process, and which may also include the addition to the article by IOP Publishing of a header, an article ID, a cover sheet and/or an 'Accepted

Manuscript' watermark, but excluding any other editing, typesetting or other changes made by IOP Publishing and/or its licensors"

This Accepted Manuscript is @ 2019 IOP Publishing Ltd.

During the embargo period (the 12 month period from the publication of the Version of Record of this article), the Accepted Manuscript is fully protected by copyright and cannot be reused or reposted elsewhere.

As the Version of Record of this article is going to be / has been published on a subscription basis, this Accepted Manuscript is available for reuse under a CC BY-NC-ND 3.0 licence after the 12 month embargo period.

After the embargo period, everyone is permitted to use copy and redistribute this article for non-commercial purposes only, provided that they adhere to all the terms of the licence https://creativecommons.org/licences/by-nc-nd/3.0

Although reasonable endeavours have been taken to obtain all necessary permissions from third parties to include their copyrighted content within this article, their full citation and copyright line may not be present in this Accepted Manuscript version. Before using any content from this article, please refer to the Version of Record on IOPscience once published for full citation and copyright details, as permissions will likely be required. All third party content is fully copyright protected, unless specifically stated otherwise in the figure caption in the Version of Record.

View the article online for updates and enhancements. 


\title{
Investigation of water microchannel boiling flow regimes using electrical sensing elements along a single microchannel
}

\author{
Mohammadmahdi Talebi ${ }^{a *}$, Sahba Sadir ${ }^{b, c}$, Keith \\ Cobry $^{a}$, Alexander Stroh ${ }^{b}$, Roland Dittmeyer ${ }^{c}$, Peter \\ Woias ${ }^{a}$ \\ ${ }^{a}$ Laboratory for Design of Microsystems, Department of Microsystems \\ Engineering (IMTEK), University of Freiburg, Freiburg, Germany \\ ${ }^{b}$ Institute of Fluid Mechanics (ISTM), Karlsruhe Institute of Technology (KIT), \\ Karlsruhe, Germany \\ ${ }^{c}$ Institute for Micro Process Engineering (IMVT), Karlsruhe Institute of \\ Technology (KIT), Karlsruhe, Germany \\ E-mail: talebi@imtek.de \\ last edit: July 21, 2019
}

Abstract. In this work, we present a method that allows for the detection of the local flow regime in a metallic microchannel using on-channel electrical sensing elements. The development of the flow regime is analyzed along a straight channel (length: $63.5 \mathrm{~mm}$, width: $1.5 \mathrm{~mm}$, height: $0.5 \mathrm{~mm}$ ) using 4 transparent electrodes fabricated on a glass lid. A constant heat flux boundary condition at the channel walls is applied to deionized water flow. Measurements are validated by recorded videos at the same locations as the sensing elements. The topology of the probability densities of impedimetric measurements shows a clear connection with visually observed flow regimes, including bubbly, slug, wavy/churn and annular flow. The method and test facilities show promising potential for further investigations into how variable channel geometries and local process parameters influence microchannel boiling.

Keywords: Microchannel flow boiling, Flow regime detection, On channel sensing elements, Indium tin oxide electrodes

Submitted to: Meas. Sci. Technol.

\section{Introduction}

Microchannel flow boiling has received much attention in recent years because of its advantages in terms of high heat transfer enhancement, even at low flow rates and low pumping powers. Hence, it has the potential to be utilized in many applications such as refrigeration systems, hybrid vehicle power electronics, cooling of IGBTs (Insulated-gate bipolar transistor), micro-heat exchangers, miniature thermal control

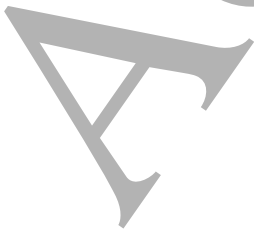


systems, and electronics $[1,2,3,4,5]$. The latent heat of evaporation of a fluid in the microchannel can extract a large amount of heat for micro cooling systems. In addition to the high latent heat flux, the high surface-to-volume ratio enhances uniformity in thermal performance, compared with typical macro-scale cooling technologies and energy transport methods. However, several challenges such as pressure instabilities, bubble expansion reversal flow and lack of critical heat flux data in the literature have limited the actual usage of two-phase flow for thermal management in microsystems [6]. The complexity of microchannel flow boiling has not been sufficiently explained and researchers are still seeking reliable and stable operating conditions for practical implementation [7]. Gaining more knowledge about boiling flow requires improvement in technology, such as through the development of local sensors, in order to provide such a quantitative database.

Fluid properties, channel diameter, heat flux, mass flux and the heated length of a microchannel are all considered in developing proposed models describing the hydrodynamics and heat transfer of boiling flow $[6,8]$. It can be understood from the literature that there are significant discrepancies between flow regime maps presented by different researchers because of variety in experimental procedurés and conditions, as well as the simple matter of individual interpretation - what constitutes a particular flow regime and what does not [9]. Many different variables affect boiling flow regimes and these would be difficult to predict only with proposed flow maps currently in the literature and with high-speed videography alone [10]. On the other hand, while general studies on flow patterns, flow transitions and void fractions are common in literature, local information about mass and thermal transport inside the channel remains very challenging to obtain. This is largely due to a relative lack of easily and inexpensively applied local sensing techniques which may be used on a much broader range of channel configurations, flow rates, and applied heat fluxes [11]. For these reasons, our current work focuses on implementing electrical sensing elements to produce local data on microchannel boiling flow. Implementing electrical sensing introduces new technical and scientific challenges, as well as opportunities, that are worth discussing. The challenges can be sorted as both experimental and analytical. Due to temperature oscillations and flow fluctuations during boiling and dependency of material properties on temperature (i.e. electrical conductivity and permittivity) and signal normalization becomes châllenging. Therefore, in this study non-normalized values are analyzed and presented in the results section. The development of sensing elements that give information directly based material properties for boiling two-phase flow provides the opportunity for better process control and enhanced performance of two-phase flow systems.

\subsection{Boiling flow in microchannels}

A universal definition is not yet established for the distinction between microchannel and macrochannel. Researchers have proposed a number of criteria for this issue. For instance, Kandlikar et al. distinguishes channels based on size: macro channels have hydraulic diameters, $D_{h}$, more than $3 \mathrm{~mm}$, minichannels with a hydraulic diameter of $200 \mu \mathrm{m}$ to $3 \mathrm{~mm}$ and microchannels with hydraulic diameter $10 \mu \mathrm{m}$ to $200 \mu \mathrm{m}$ [4]. Harirchian and Garimella defined the distinction between micro and macro size channels based on confinement of bubbles [12]. In our study, we consider a microchannel
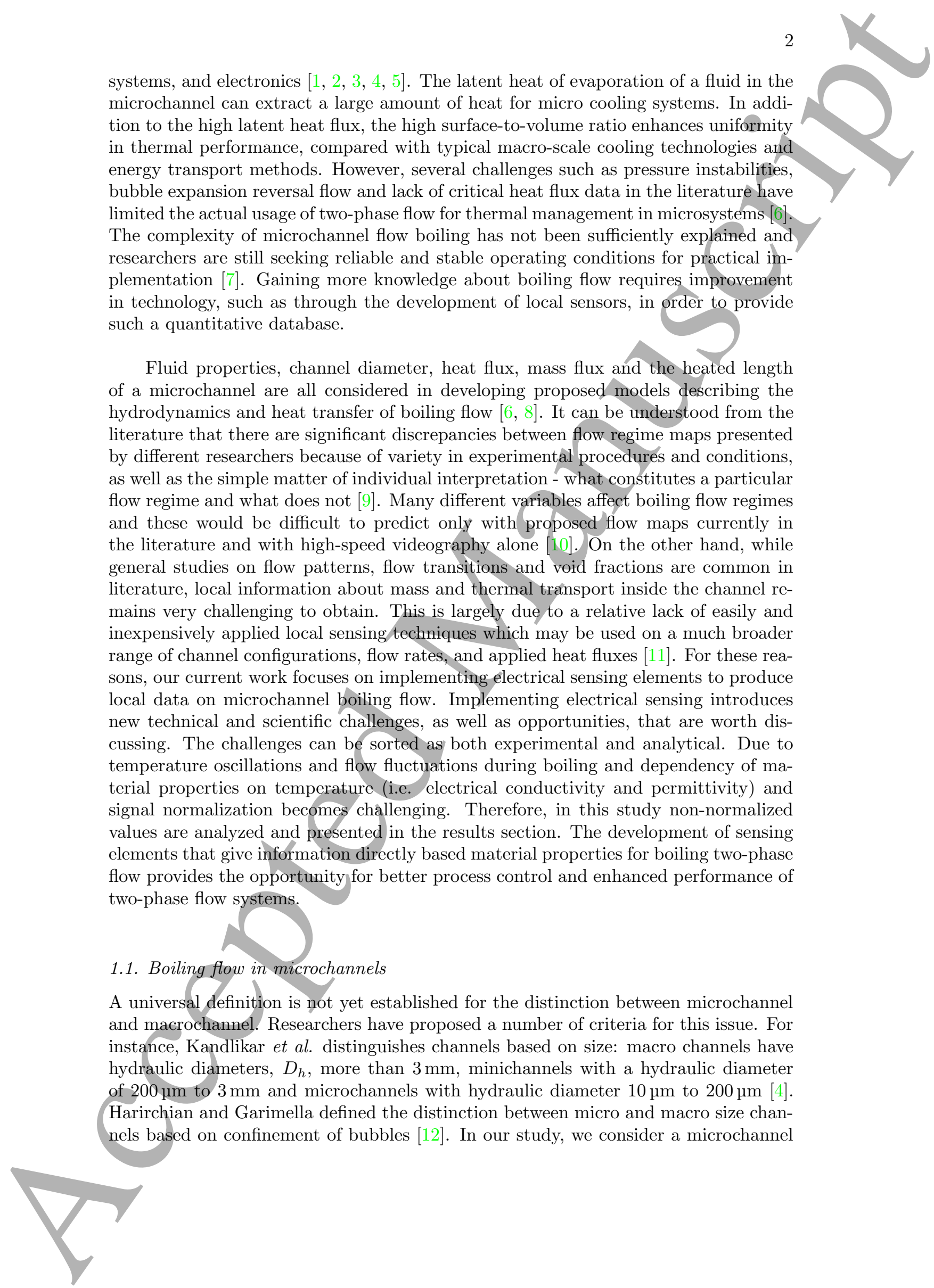
to be one with hydraulic diameter less than $1 \mathrm{~mm}$ - as a result of this channel size, bubble confinement may be observed.

Despite the many studies on flow boiling in microchannels, the physical mechanisms behind the evaporation processes are still unclear, due to the extremely complex thermal and hydrodynamic interactions. The evaporative process and the convective flow mechanics in microchannels (as well as macrochannels) are highly coupled, leading to this complex behavior. The fact that the Taylor instability law may not be applied to describe interfacial processes is a special consideration in flow boiling scenarios. A scale analysis by Kandlikar [13] suggests that surface tension and evaporation momentum forces play a dominant role at the microscale. The evaporative process inside the microchannel induces signifcantly different flow patterns, compared to macrochannels, due to confinement effects. The flow patterns are the result of the action of forces, such as the surface tension, inertia shear, gravity and evaporation momentum at the liquidvapor interface. Gravitational forces are considered here to be negligible. The heat flux plays an important role in the hydrodynamics of boiling flow in a microchannel and high wall superheating is required at boiling incipience. Researchers have characterized the influence of the channel dimension on the flow patterns, as confirmed by experimental visualization $[14,15]$.

Flow regime identification is one of the most important aspects to consider in seeking to describe the governing mechanisms of microchannel flow boiling. Many researchers have classified gas/liquid flows in microchannels, as bubbly flow, slug flow, annular flow and annular/churn flow $[12,16]$. The observed patterns in minichannels are typically reported to be similar to those observed in macrochannels. By contrast, some additional features are noted for microchannels; (1) confined bubble expansion, (2) decrease of the liquid film thickness surrounding the vapor slug, (3) lack of mist flow, and (4) diminishing churn and stratified flow. Consequently, changes in channel diameter and operating condition (i.e. heat flux, mass flux, and pressure) exert even more influence on the configuration of flow regimes [4, 5]. Figure 1 presents representative flow regime maps showing the effect of microchannel size, as well as mass and heat flux, on evaporation. The corresponding flow regimes in Figure 1 may be described as follows;

- Bubbly flow: In bubbly flow, the vapor phase is distributed as discrete bubbles in a continuous liquid phase. The bubbles are smaller than the channel diameter, as shown in Figure 1-a, but may vary widely in size. This flow regime is mostly observed near to the inlet at high mass flow rates.

- Slug flow: As the vapor bubbles grow and coalesce, larger bubbles form, filling the

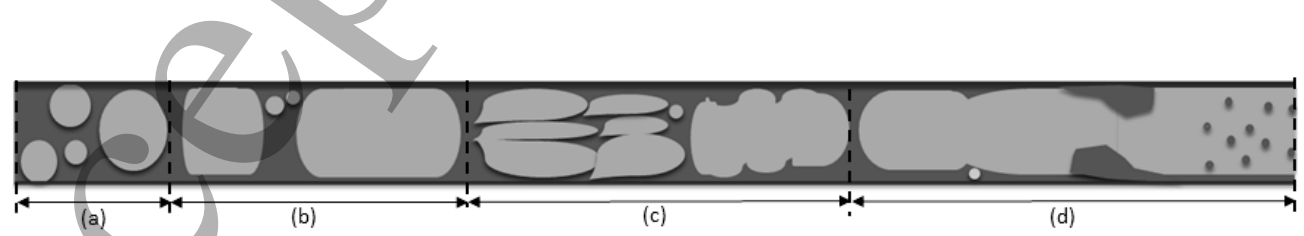

Figure 1. Schematic of boiling flow regimes in microchannels and minichannels. a) bubbly flow .b) slug flow . c) churn and wavy annular flow . d) annular flow and mist flow.

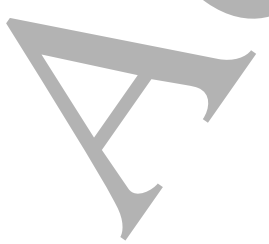


width of the channel and elongating in the axial direction along the channel. They often demonstrate a "bullet shape", as shown in Figure 1-b, and are separated by liquid slugs. One key feature that affects bubble velocity and mass transport is the fact that the bubble is surrounded by a thin film of liquid, i.e. the gas is not directly in contact with the channel wall.

- Churn flow and wavy annular flow: At low and medium fluid flow rates, the liquid slugs begin to disappear (Figure 1-c) and the large vapor core breaks into unstable collapse patterns; this results in a highly disturbed flow pattern with a churning or oscillatory motion of liquid film on the wall.

- Annular flow: A liquid film remains on the channel wall with a continuous central vapor core. The film liquid thickness tends to decrease with increasing heat flux. At higher mass flux, the annular flow may be disturbed periodically with chaotic waves (wavy annular flow).

- Mist flow and Post-dryout: The liquid film surrounding the vapor core becomes thinner as heat flux increases, leading to dryout at the wall surface. The vapor core becomes unstable and very small liquid droplets may be entrained in it. Post-dryout inverted-annular flow may appear at a critical heat flux, when the channel walls completely dry out.

There are several works published reporting flow maps and prediction methods. However, these prediction methods mainly depend on special experimental boundary conditions such as channel cross section dimensions and aspect ratio, channel path, fluid properties, mass flux, heat flux, solid material properties and fluid under test and do not provide universally applicable prediction information about local flow regime in a microchannel. Consequently large differences and high uncertainties in the predictions are present $[17,18]$. It has been shown that different channel geometries and designs can influence the flow regimes that develop, and subsequently the heat transfer mechanisms - i.e. Dean mixing in curved channels or Taylor re-circulation in fluid slugs in segmented flow $[19,20]$. This has led us trying to implement electrical sensors for flow regime detection, in order to use direct measurement and avoid these prediction uncertainties.

\subsection{Electrical sensing for two-phase flow}

Highspeed videography alone cannot be used for regime detection in general laboratory or industrial applications, as optical access to the channel may not be available. Therefore, developing a general applicable flow regime detection technique for boiling flow by other means is necessary. In the field of multiphase flow sensing, researchers have implemented electrical sensing elements using different methods such as parallel plate resistive/capacitive/impedimetric techniques, which often are based on wire mesh or two wire systems. There are examples in the literature on both the macro [21, 22, 23] and micro scales $[24,25,26,27]$ that show how different fields of application, such as the oil and gas industry, fine chemicals production or even bioanalytics can benefit from integrated sensing systems for two phase flows. The common point in all of these studies is that the main objective is to detect local void fraction and flow regime patterns [28, 24, 29, 22]. Implementation of the sensing elements is challenging in microchannels due to significant noise, inherent variability in fabrication tolerances,
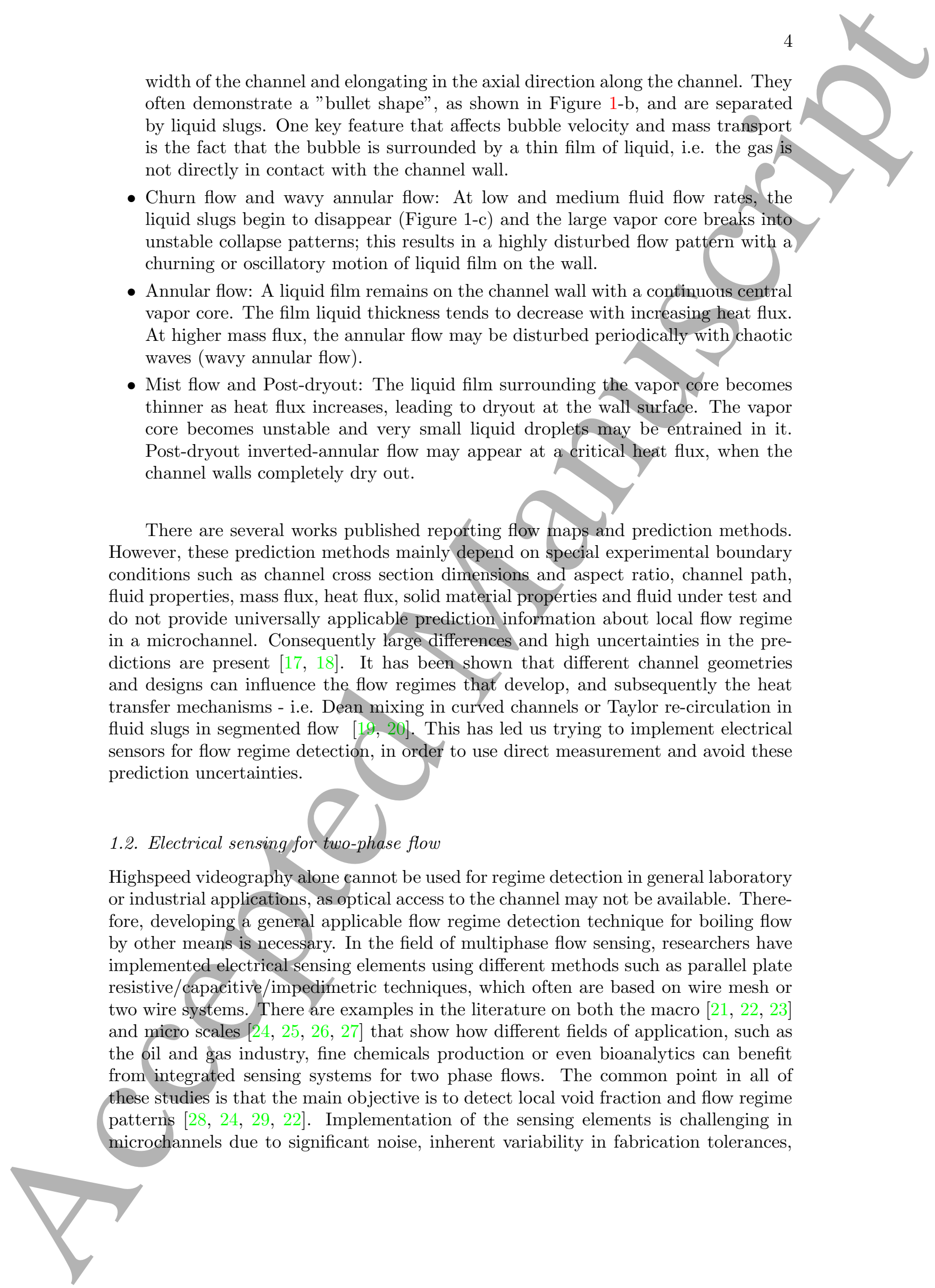
and uncertainites in experimental conditions which may play an outsized role in the results. Channel geometry (i.e. cross-section shape: cylindrical, rectangular, other), electrode geometry, electrode contact with fluid, and fluid/vapor electrical properties (conductivity and permittivity) play key roles in understanding the performance of an electrical sensing system. Consequently each electrode implementation (shape, size, position, connection scheme...) needs specific calibration and post processing analysis.

There are more examples in the literature on implementation of electrical sensing in macro-scale than micro-scale systems. On the macro-scale, sensing elements have with helical-, ring-, or concave-shaped electrodes have been demonstrated [30, 22]. Ahmed reports that with an excitation frequency of $1 \mathrm{MHz}$, tests of two phase flow with both ring-type and concave-type sensors show a linear relation between void fraction and capacitance independent of the specific flow pattern [30]. The capacitance measurements were further analyzed to identify the flow pattern using the Probability Density Function (PDF) and Power Spectrum Density (PSD) of the signal measurements. These could distinguish between slug and elongated bubble flow [30, 31]. Fossa has investigated ring-type conductivity probes placed on the internal wall of a pipe with air and tap water inside the pipes (70 $\mathrm{mm}$ i.d. and $14 \mathrm{~mm}$ i.d.) [32]. A flow regime calibration based on observed annular flow, stratified and bubbly flow made it possible to measure the liquid fraction in the pipe [32]. In an experimental work on vertical two-phase flow presented by Mi et al., it is shown that void fraction fluctuations that are measured by electrical impedance are statistically in proportion with observed measurements where various flow regimes are present (i.e single-phase liquid or gas, bubbly flow, slug flow, churn flow, annular flow) [21]. Using the database of these measurements, a supervised and self-organized neural network system was developed to detect flow regimes [21]. For the gas and oil industry, capacitive sensors over pipes have received attention with the motivation of collecting void fraction information for monitoring, controlling and optimizing crude prôduction [22]. A general observation to be made, after reviewing the above-mentioned works, is that each sensor system requires its own individual calibration and analysis procedure, which is tailored to the fluid properties, electrode geometries and channel configuration. FEM methods have been used in several cases to model electric field for different flow regimes to anticipate sensor response [22, 33, 34].

In microchannels, as opposed to macrochannels, electrical sensing elements in tests with two phase flows are typically configured with parallel plate or interdigitated electrodes on either one or opposing channel walls [24, 26, 27, 35, 36]. In the work presented by Paranjape et al. and Valiorgue et al., two flush-mounted electrodes were used to perform electrical sensing on adiabatic two phase flow at room temperature $760 \times 760 \mu \mathrm{m} /$ microchannel $[24,29]$. The analysis of the probability density function (PDF) of normalized admittance, which was obtained by using a kernel density function, showed a clear relation to the flow regime [24, 29]. Gijsenbergh and Puers reported a system with parallel plate electrodes in an array of $100 \mu \mathrm{m}$ wide to $500 \mu \mathrm{m}$ deep silicon etched channels, with the readout circuit measuring the capacitance. At room temperature, capacitance relation to the void fraction was reported as being linear in water and air media [27]. Co-planar gold electrodes, which were in direct contact with kerosene-water slug flow in $1 \mathrm{~mm} \times 1 \mathrm{~mm}$ showed the potential to analyze the speed and length of passing slugs with $300 \mathrm{~Hz}$ AC excitation signal (at room temperature) [35]. These works show that the relative electrode location, shape, boundary
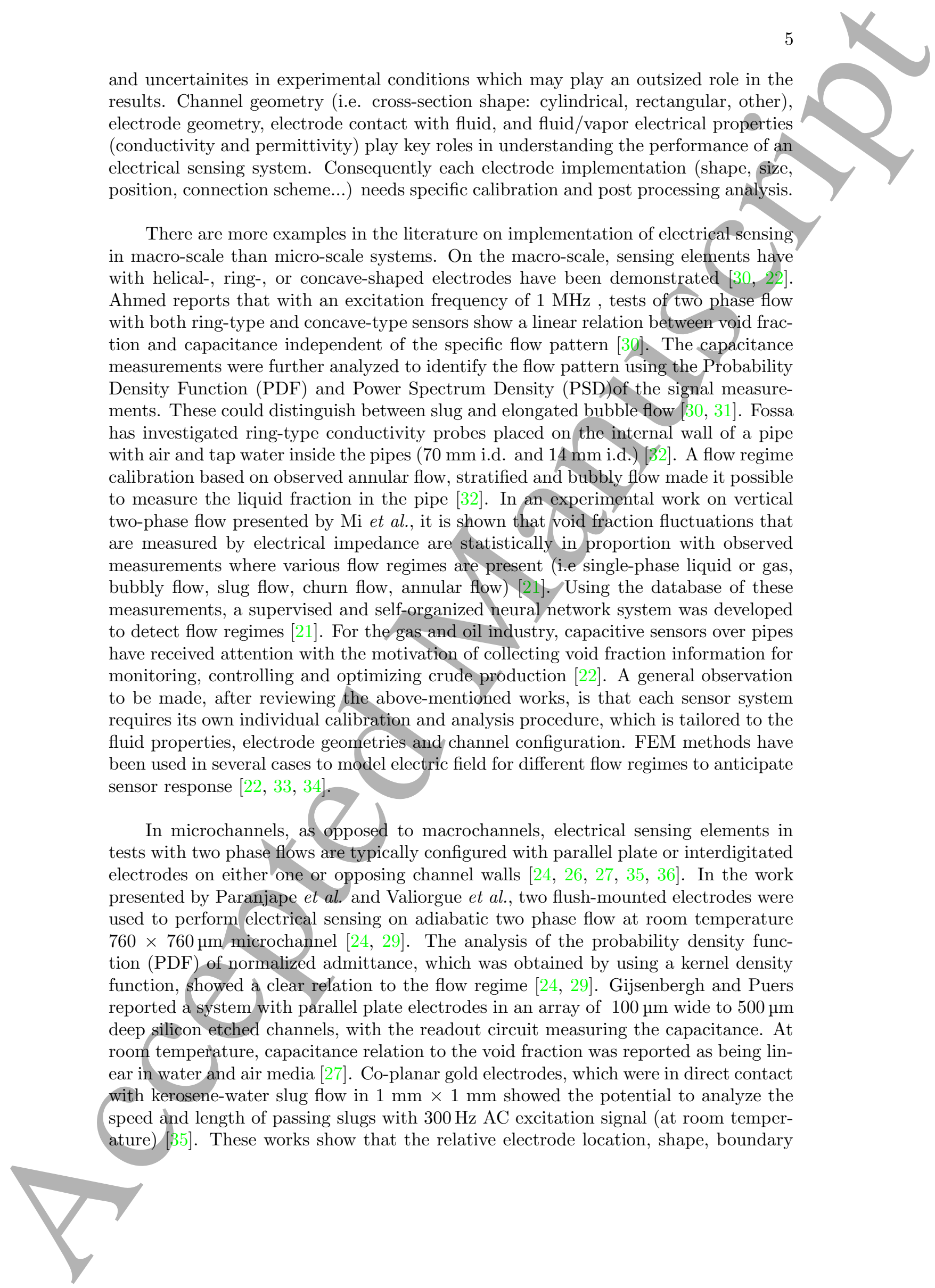
conditions, as well as system noise, influences the sensor spatial resolution, sensitivity and linearity [29, 22]. Boiling flow in particular presents a challenge in managing and accounting for thermal noise.

The selection of which frequency or range of frequencies to employ in any given $\mathrm{AC}$ electrical measurement is also critical to the success of the sensing system. One must have enough insight into the physical and electrical properties of the system components such as the fluids, test housing, and electrical measurement equipment, to be able to build an equivalent electrical circuit; this can elucidate which frequencies are likely to yield measurable impedimetric differences as a function of void fraction in the channel, given other fixed parameters such as channel and electrode dimensions as well as ancillary electrical parasitics in the measurement systems. Electrochemical processes at the electrodes should be avoided and polarization effects as a function of frequency should be understood. With respect to our work, Valiorgue et al. suggests that the electrical impedance in the frequency range between 10 to $100 \mathrm{kHz}$ for water is mainly resistive and for gas phase is capacitive [29].

\section{Experimental method}

In the current work we implement a system for the direct electrical monitoring of water flow boiling in a straight microchannel (width: $1.5 \mathrm{~mm}$ - depth: $0.5 \mathrm{~mm}$ - length: $63.5 \mathrm{~mm}$ ) in order to assess sensor response compared with real-time video. Electrical monitoring is far less expensive than video, and is morê practical to apply to industrial systems. Here, the video serves as validation of the interpretations of electrical sensor readings. A schematic model of the experimental test rig is shown in Figure 2. DI-water was pumped through a degasser (Biotech DEGASi PLUS Semi-Prep) before entering the test housing. A micro annular gear pump (HNP mzr-7205) produces minimal pressure fluctuations inside the microchannel while providing a stable loop flow. The housing has a modular design which includes a heater block with resistive heater cartridges. The flow channel is machined into a replaceable plate, which is covered by a glass lid and is sealed in the compression housing assembly. The channel plate may be easily replaced in order to allow testing with different channels cross-sections and paths (i.e. straight, zig-zag, meander, spiral,...). The housing simultaneously provides fluidic as well as electrical contact, while regulating the applied heat flux, and is thus a central, non-trivial component of this work. Working electrodes on the glass are fabricated using wet-etched indium tin oxide (ITO) and covered with a hard-baked SU8 layer. Details regarding cleanroom fabrication process are explained in our previous published works $[25,37,38]$. The design of the housing and assembled modules are explained in detail in the previous publications as well [37, 38]. For every experiment condition shown in Figure 4, video recording of the boiling flow was performed with a DSLR camera (Cànon 500D) mounted to a objective with a magnification of $4 \mathrm{X}$ and a high speed camera (CHRONOS) in all electrical sensor locations. For each experiment, the heat flux and the flow rate were the set parameters, and 15000 impedance data points in a time series were recorded. All impedance measurements were performed with an LCR-meter (Hioki-IM3536) connected to the PC. The data sampling rate varies from $\sim 270 \mathrm{~Hz}$ to $\sim 100 \mathrm{~Hz}$ for different tests due to LCR-meter's internal settings for auto range detection.

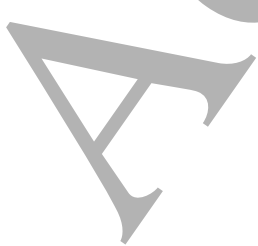

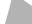

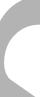




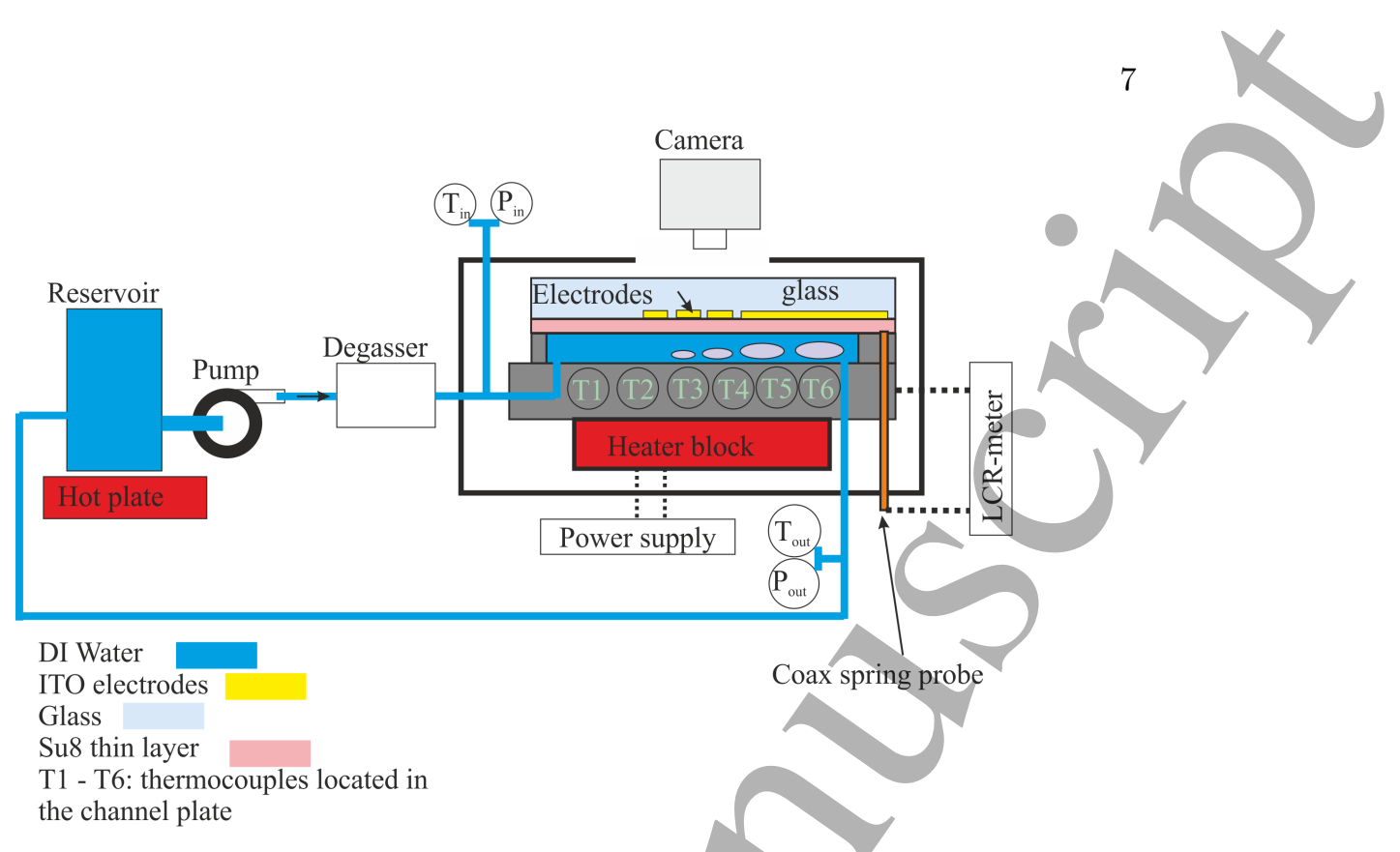

Figure 2. Experimental test setup schematic

On the glass lid, 4 optically transparent ITO (indium tin oxide) electrodes are present, providing the opportunity to perform electrical measurements while simultaneously taking video at the same location. Over the channel area, ITO is passivated with a hard-baked layer of SU8-2000.5, which has a thickness of $\sim 700 \mathrm{~nm}$. There is a patterned opening window in the SU8 at the contact pad location for the ITO electrode which allows spring probes to make electrical contact. SU8 is an optically transparent, photopatternable material suitable for patterning fine features by photolithography. It is very chemically and mechanically robust, making it ideal for many thermal and chemical microfluidic processes, such as flow boiling. The fabricated glass lid with ITO electrodes is shown in Figure 3-b. There are 6 thermocouples located in the channel plate with a distance of $500 \mu \mathrm{m}$ beneath the channel bottom wall. A cross-sectional schematic showing the location of the electrodes and heaters is shown in Figure 3-a. The channel geometry plays a major role in the resulting two phase flow. In these experiments, rectangular channels of $1500 \mu \mathrm{m} \times 500 \mu \mathrm{m}$, and were machined in stainless steel. The channel plate frame dimensions are $75 \mathrm{~mm} \times 25 \mathrm{~mm}$.

The glass lid is compressed over the metallic stainless channel plate with a sealing o-ring ( Figure 3). A summary of the experimental parameters relating to the channel size, heat flux and impedimetric measurements are shown in Table 1. The channel has $63.5 \mathrm{~mm}$ total length and the sensors are located at S1: $17.25 \mathrm{~mm}, \mathrm{~S} 2: 27.25 \mathrm{~mm}, \mathrm{~S} 3$ $37.25 \mathrm{~mm}$ and S4: $47.25 \mathrm{~mm}$ from the start of the channel. The ITO electrode size is $2 \mathrm{~mm}(\mathrm{~L}) \times 1.7 \mathrm{~mm}(\mathrm{~W})$. According to several reports in literature, surface roughness of the boiling bed might play rule in emerging of the vapor bubbles [39, 40]. Since the metallic channel plate is heated, we can consider the influence of SU8 layer surface on top of the channel on the boiling flow negligible. 

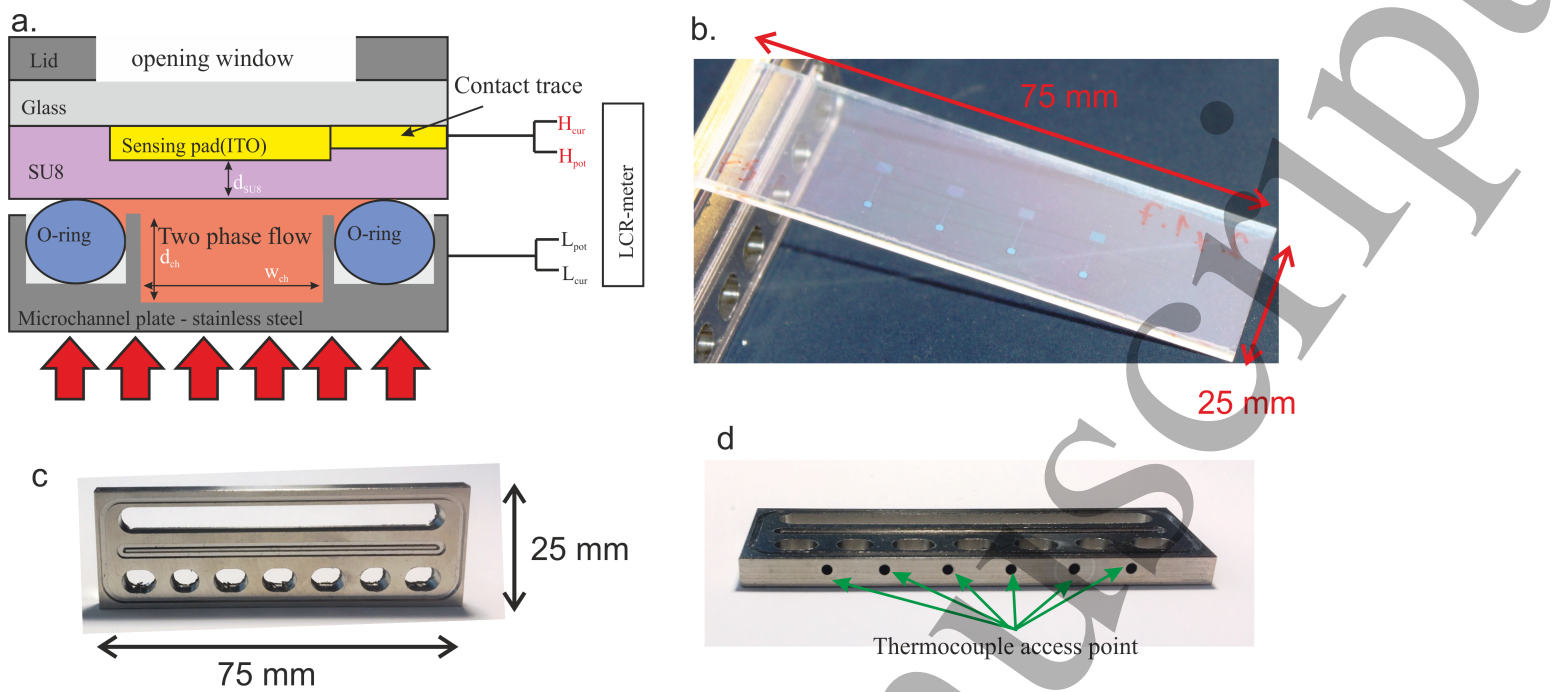

Figure 3. a. Channel cross section schematic. b. Photograph of the glass lid with ITO electrodes. c. Channel plate front view. d. Side/view of channel plate.

Table 1. Experimental parametérs [41, 42, 43].

\begin{tabular}{|c|c|c|}
\hline$\overline{\text { Property }}$ & Unit (uncertainty) & Value \\
\hline Channel hydraulic diameter & $\mu \mathrm{m}$ & 750 \\
\hline Flow rate & $\begin{array}{l}\mathrm{ml} \cdot \min ^{-1} \\
\text { (less than } 1 \% \text { Coefficient of variation } \mathrm{CV} \text { ) }\end{array}$ & 0.5 to 4 \\
\hline Channel wall temperature & ${ }^{\circ} \mathrm{C}(( \pm 0.2 \%$ Rdg. $)+( \pm 0.8))$ & 86 to 136 \\
\hline Total heaters applied power & Watt & 20 to 32.3 \\
\hline $\begin{array}{l}\text { Measurement excitation } \\
\text { frequency }\end{array}$ & $\mathrm{kHz}($ less than $0.01 \%=5 \mathrm{~Hz})$ & 50 \\
\hline $\begin{array}{l}\text { Measurement potential } \\
\text { peak to peak }\end{array}$ & $\mathrm{V}( \pm 60 \mathrm{mV})$ & $\mathrm{V}(5)$ \\
\hline Reynolds number @ $90^{\circ} \mathrm{C}$ & - & 25.66 to 205.25 \\
\hline
\end{tabular}

\section{Experimental results}

Impedance measurements of active boiling flow were performed under 25 different combinations of flow rate and applied heat with working electrodes located at four locations along the channel. Based on the performed experiments, a flow regime map was developed using video recordings over four sensor positions along the channel (Figure 4). In these set of experiments, no pre-heating is applied on the flow. DI-water enters housing with room temperature and heats up along the channel. This enhances the chance of having several flow regimes in a constant flow rate and power along the channel as shown in Figure 4. It is notable from the flow map that the further from the entrance of the channel, the more boiling occurs (Figure 4). Differentiation between the flow regimes is based on the definitions explained in Section 1.1. We observed that at lower flow rates, bubbly flow is not established, rather slug and annular flows are predominant. When the mass flux increases, we see bubbly flow even at low heat flux with spherical shaped bubbles. On the other hand, slug flow is observed at low heat

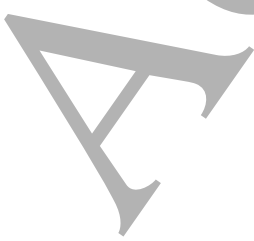


flux. By increasing the heat flux, churn flow and annular flow appear. The housing as a whole has a relatively high thermal mass, so in order to allow for the entire test setup to come to thermal equilibrium, impedance measurements were not taken until minimum 20 minutes after the heater cartridges power and flow rate were set. Figure 5 represents example pictures of annular flow and slug that is recorded with camera.

Because of the sampling rate (maximum $270 \mathrm{~Hz}$ ), the flow rate, and the electrode size, the detection of individual small single bubbles is not possible. Assemblies of small bubbles, however, can contribute to a net detectable change in the dielectric constant within the sensing volume. In this set of experiments, since there is no active temperature controlled pre-heating before test housing, DI-water enters the test housing at room temperature. There is a measured temperature gradient along the length of the microchannel, therefore, it is expected to see different flow regimes under the above mentioned sensing points. MATLAB is used for drawing probability density graphs (Figure 6, Figure 7, Figure 9). After analyzing the videos of the boiling in

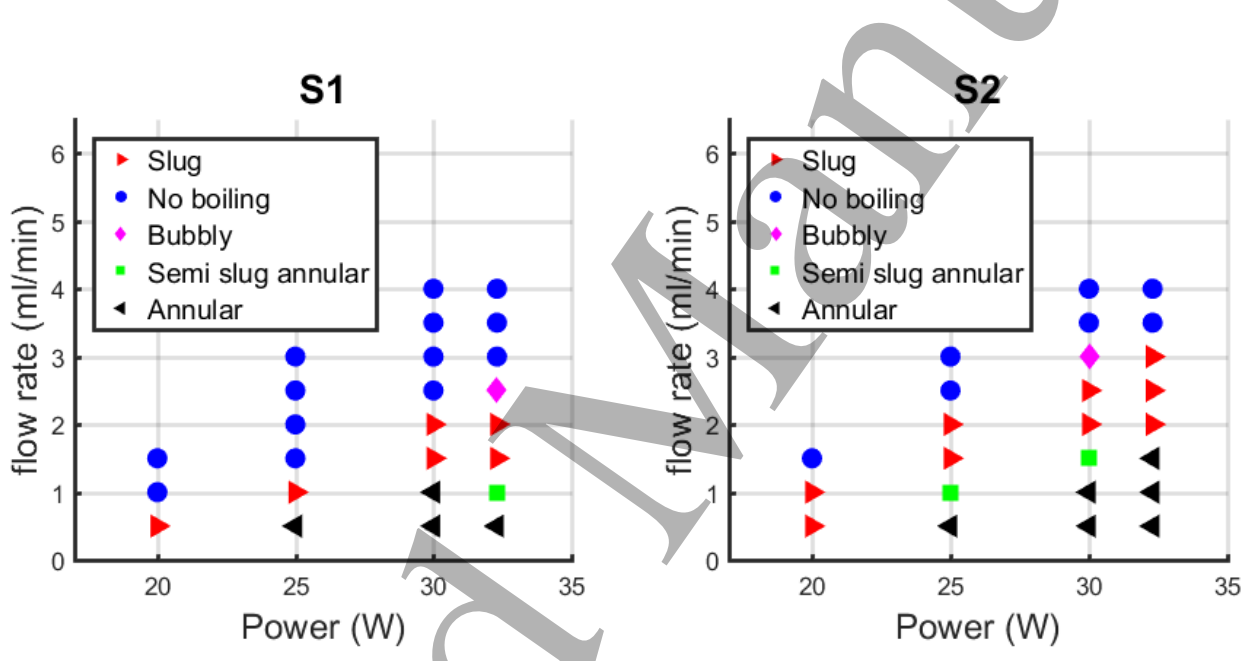

S3

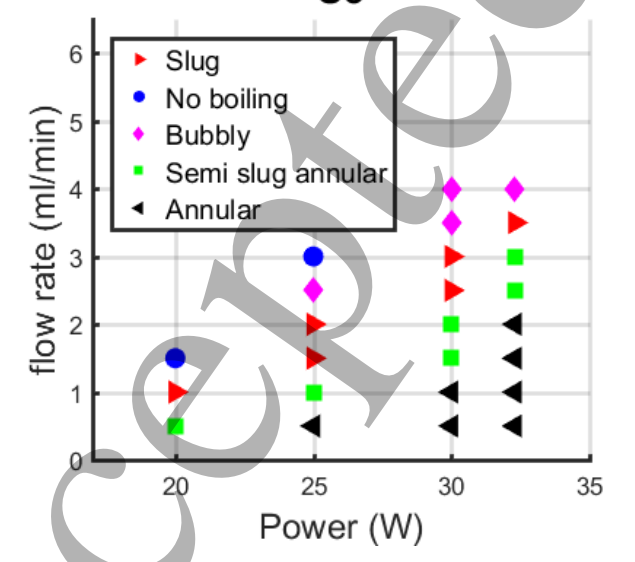

S4

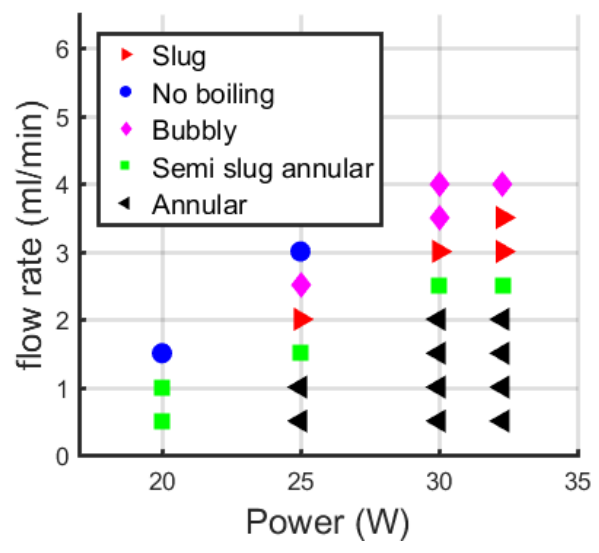

Figure 4. Flow map of boiling tests characterized by visual observation at the four sensor locations (S1: $17.25 \mathrm{~mm}, \mathrm{~S} 2: 27.25 \mathrm{~mm}, \mathrm{~S} 337.25 \mathrm{~mm}$ and S4: 47.25 $\mathrm{mm}$ from the inlet of the channel) (1) (1) r

\author{
(1)
} 政 . .

8


channel in each location and sorting them based on flow regime, the shape of probability density curve is compared with the detected flow regime. In bubbly flow, for example, a large count ratio, $\frac{n_{i}}{N}$ would occur at low void fraction while smaller count ratios would exist at the higher void fractions [44]. In this work, low void fraction corresponds with lower measured channel impedance, as the liquid phase is more conductive and has a higher dielectric constant than the vapor phase. Physically, the PDF curve shape corresponds to the contribution of each kind of bubble in the measurement [24]. Assuming the fact that enough measurement points were measured for a sufficiently long time - "long" being relative to periods of fluctuations in the channel - the process under measurement is statistically stationary and the topology of PDF curve must be reproducible [44]. The PDF is a histogram of impedance versus count. The shape of the PDF can be interpreted as representing different flow regimes. I.e. a strong peak at a high impedance value with no other peaks would likely indicate annular flow with a large void fraction. Similarly, two moderate peaks at high and low impedance values may indicate slug flow, where over the period of the measurement, the presence of fluid and vapor was similar. More detailed investigation into the shapes of the PDFs may allow one to distinguish between bubbly flow and slug flow - in both cases, there may be a similar relative ratio of fluid and vapor over the full measurement time, but the distributions are different. It must be noted that in the following sections, the mentioned Reynolds numbers are calculated based on viscosity of Di-water in $90^{\circ} \mathrm{C}$, which is slightly below saturation temperature.

\subsection{Watt}

As the flow rate is decreased, we observe the appearance of boiling inside the channel at the first sensor location at $0.5 \mathrm{ml} / \mathrm{min}(\mathrm{Re}=25.7)$. The impedance probability 
density plots with a heat flux of $20 \mathrm{~W}$ are shown in Figure 6. The video of S1 shows only slugs filling the sensing area when the flow rate is on $0.5 \mathrm{ml} / \mathrm{min}$ and no boiling happens in this location after the flow rate is increased to $1 \frac{\mathrm{ml}}{\mathrm{min}}(\mathrm{Re}=51.3)$ and $1.5 \frac{\mathrm{ml}}{\mathrm{min}}$ $(\mathrm{Re}=77.0)$. Video observation for the $0.5 \frac{\mathrm{ml}}{\mathrm{min}}$ flow rate suggests that some of the slugs that appear in the impedance measurement signal are due to backward vapor expansion of bubbles produced downstream of S1. Recorded videos of the S2, S3 and $\mathrm{S} 4$ locations at $0.5 \frac{\mathrm{ml}}{\mathrm{min}}$ show slug flow in $\mathrm{S} 2$ that has a transition to annular flow at the S3 and S4 locations. By analyzing the impedance probability density curves at the four sensor locations when the flow rate is $0.5 \frac{\mathrm{ml}}{\mathrm{min}}$, S2 shows a probability density with one peak at high impedance (vapor) and the other peak at low impedance (liquid). Due to the small number of passing/filling slugs in S1 location, the peak of the vapor section is very small. Annular flow with an oscillating liquid thin layer (wavy-annular) shows a different PDF curve (i.e. S4, $0.5 \frac{\mathrm{ml}}{\mathrm{min}}$ ) with a single peak for the curve at high impedance.
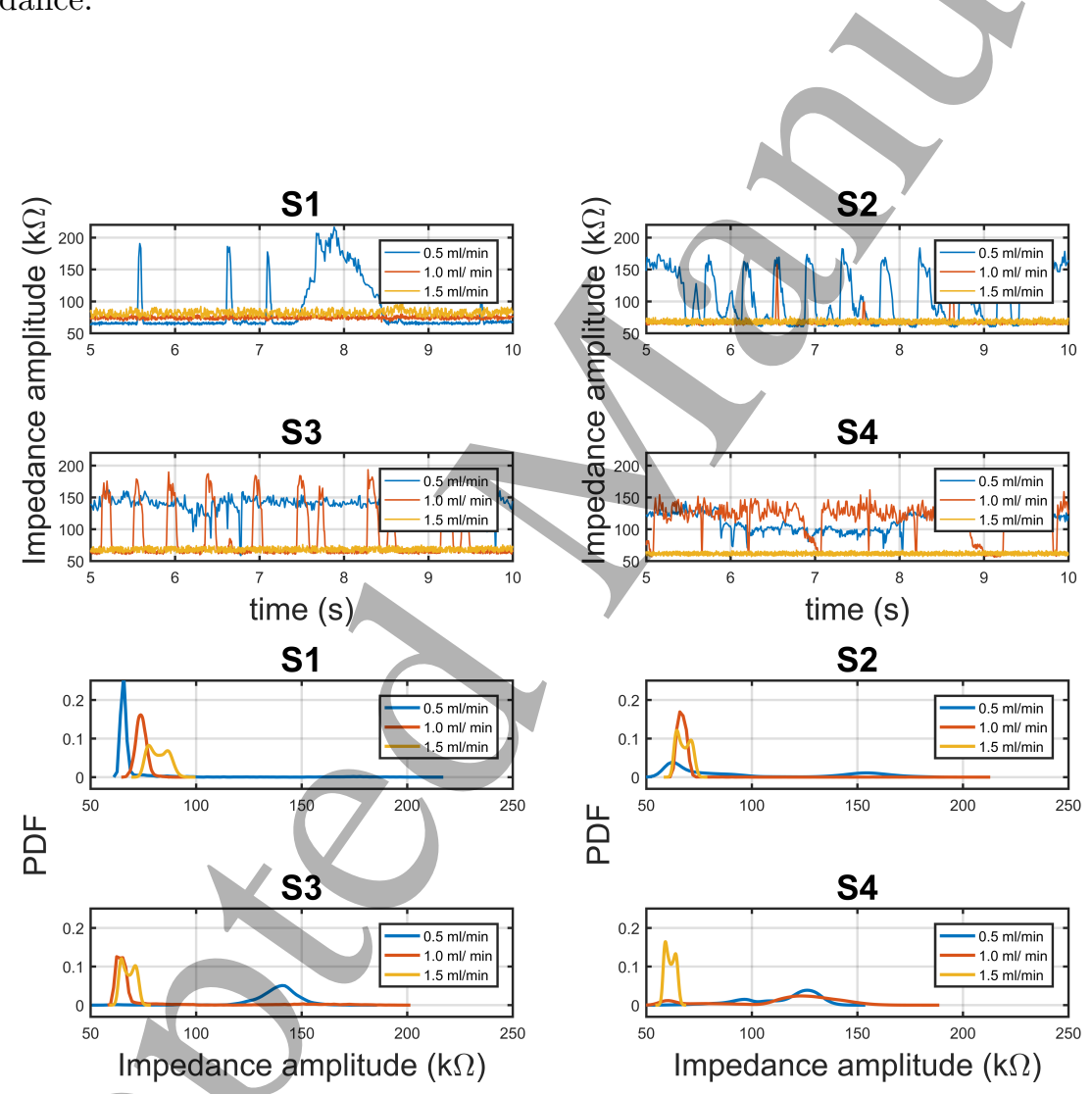

S2

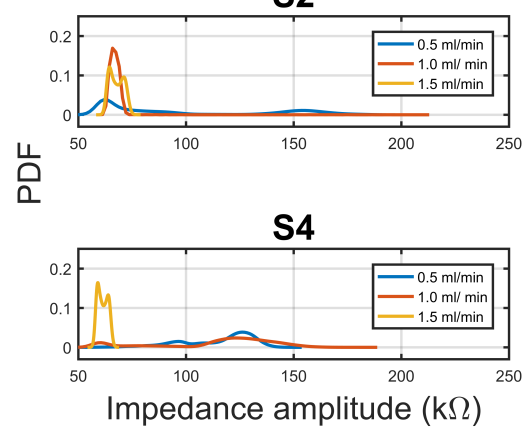

Figure 6. Impedance amplitude measurements and probability density on 20 Watt

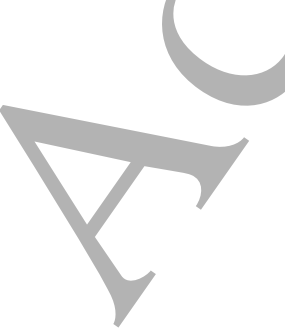




\section{2. $25 \mathrm{Watt}$}

By increasing the heater power to $25 \mathrm{~W}$, at $0.5 \frac{\mathrm{ml}}{\mathrm{min}}(\mathrm{Re}=25.7)$, all 4 sensors show annular flow, which have corresponding PDF curves with a single peak at high impedance. The impedance amplitude measurements and probability density plots of the measurements are shown in Figure 7. The video shows a continuous vapor core in the channel in the annular flow shape at all 4 locations. At the S1 location, the signal value decreases to the baseline of water $(\sim 60 \mathrm{k} \Omega)$ with frequent jumps to the vapor core impedance at $1 \frac{\mathrm{ml}}{\mathrm{min}}$ and $1.5 \frac{\mathrm{ml}}{\mathrm{min}}$. Considering the videos, for $1 \frac{\mathrm{ml}}{\mathrm{min}}$ flow rate, the S1 location shows some slugs passing or filling the sensing area, S2 shows slug/annular flow and S3 and S4 show continuous annular flow. When the flow rate increases to $1.5 \frac{\mathrm{ml}}{\mathrm{min}}(\mathrm{Re}=77.0)$, a complete transition between flow regime can be observed from recordings along the channel. In the S1 location, scattered bubbles are passing while $\mathrm{S} 2$ shows a denser bubbly flow passing in the channel. With the same experimental parameters $\left(25 \mathrm{~W}, 1.5 \frac{\mathrm{ml}}{\mathrm{min}}\right)$, S3 shows a transition from slug/annular flow and S4 location shows a complete annular flow regime. The observation of the flow recordings for $2 \frac{\mathrm{ml}}{\min }(\mathrm{Re}=102.6)$ shows that in the location of S1 and S2 no boiling is occurring. At this flow rate, the videos show slug flow at the locations of both S3 and S4.

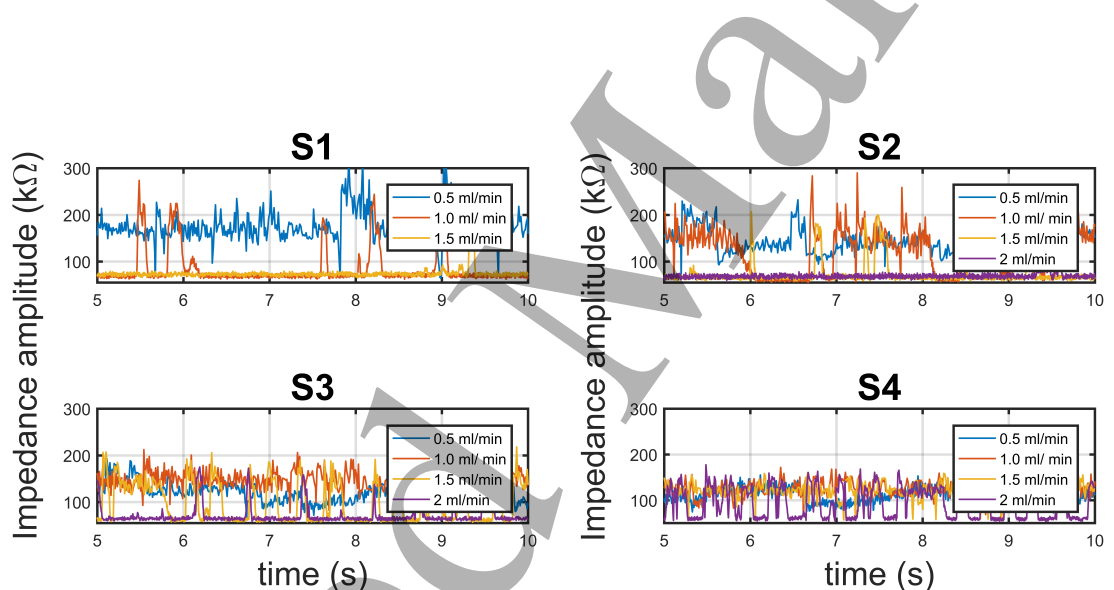

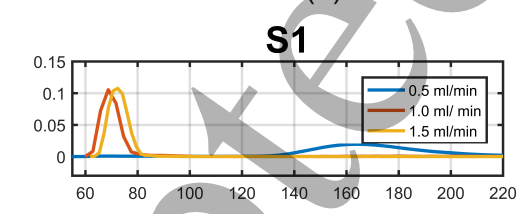
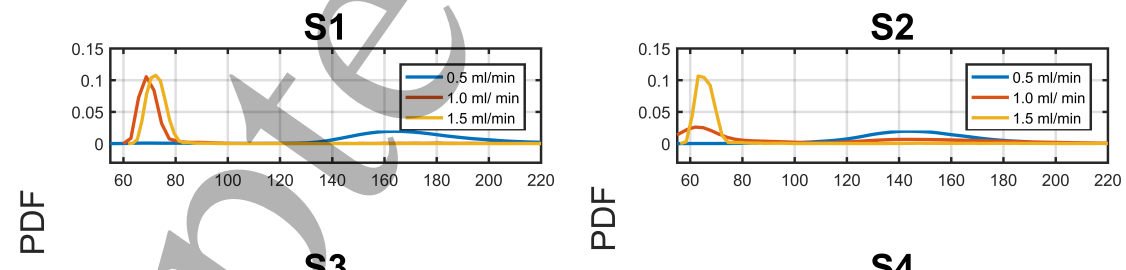

㟔

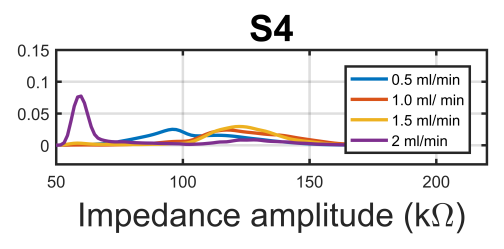

(1) 
S1

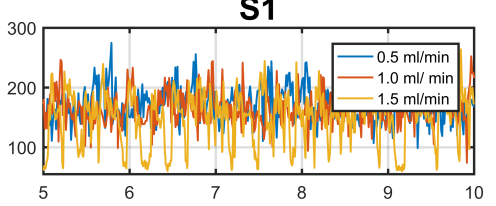

S2

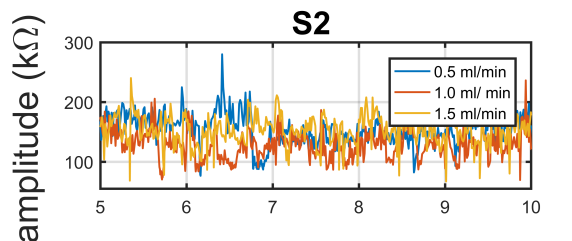

S3

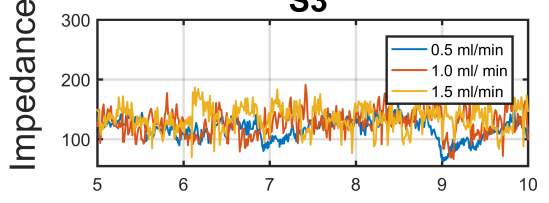

S4

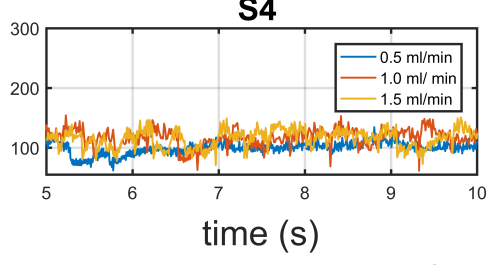

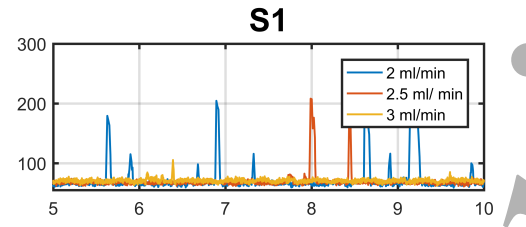
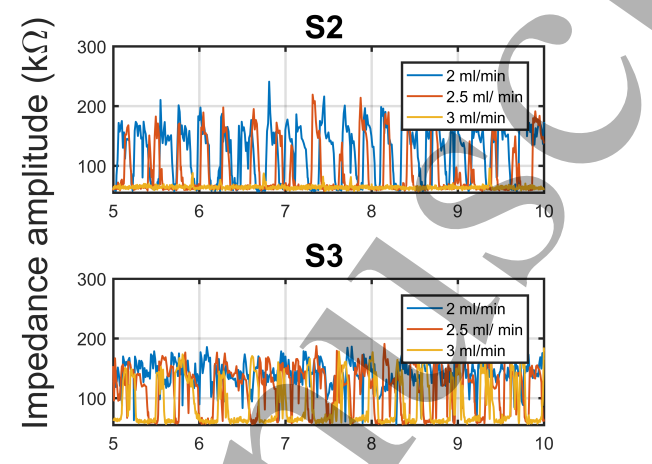

S4

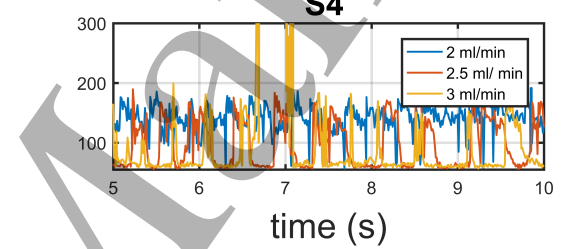

Figure 8. Impedance amplitude measurements at 32.3 Watt for different flow rates

\subsection{3 Watt}

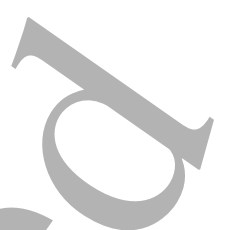

We observed annular flow in four sensors positions along the length of the microchannel for high heat flux $(30 \mathrm{~W}$ and $32.5 \mathrm{~W})$ and low mass flux $\left(0.5 \frac{\mathrm{ml}}{\mathrm{min}}\right)$. The results for these four points are particularly interesting, since the peak of probability density curve of the measurement has a shift to lower impedance in S4 rather than S1. The major difference in the observed flow patterns is the thickness of the liquid film about the vapor core and the dry-out pattern. It was observed that the liquid film periodically dried and re-wet. At the S3 and S4 locations, the vapor core initially occupied the center of the channel. Then the vapor core rapidly grew and eventually approached to the walls leading to partial dry-out. Additionally, due to the high temperature difference in the contact area between the saturated vapor and the glass cover, condensation occurred and vapor core shrunk and quickly re-wet the walls. The high temperature difference with the outside environment is the main reason of cyclic re-wetting on the glass surface. It is difficult to recognize all details of the process given the speed and quality of the current videography system. We interpret that the high heat flux with low mass flux input indicates intensified evaporation for a fast-growing vapor core and

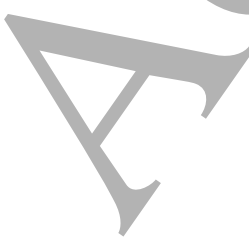



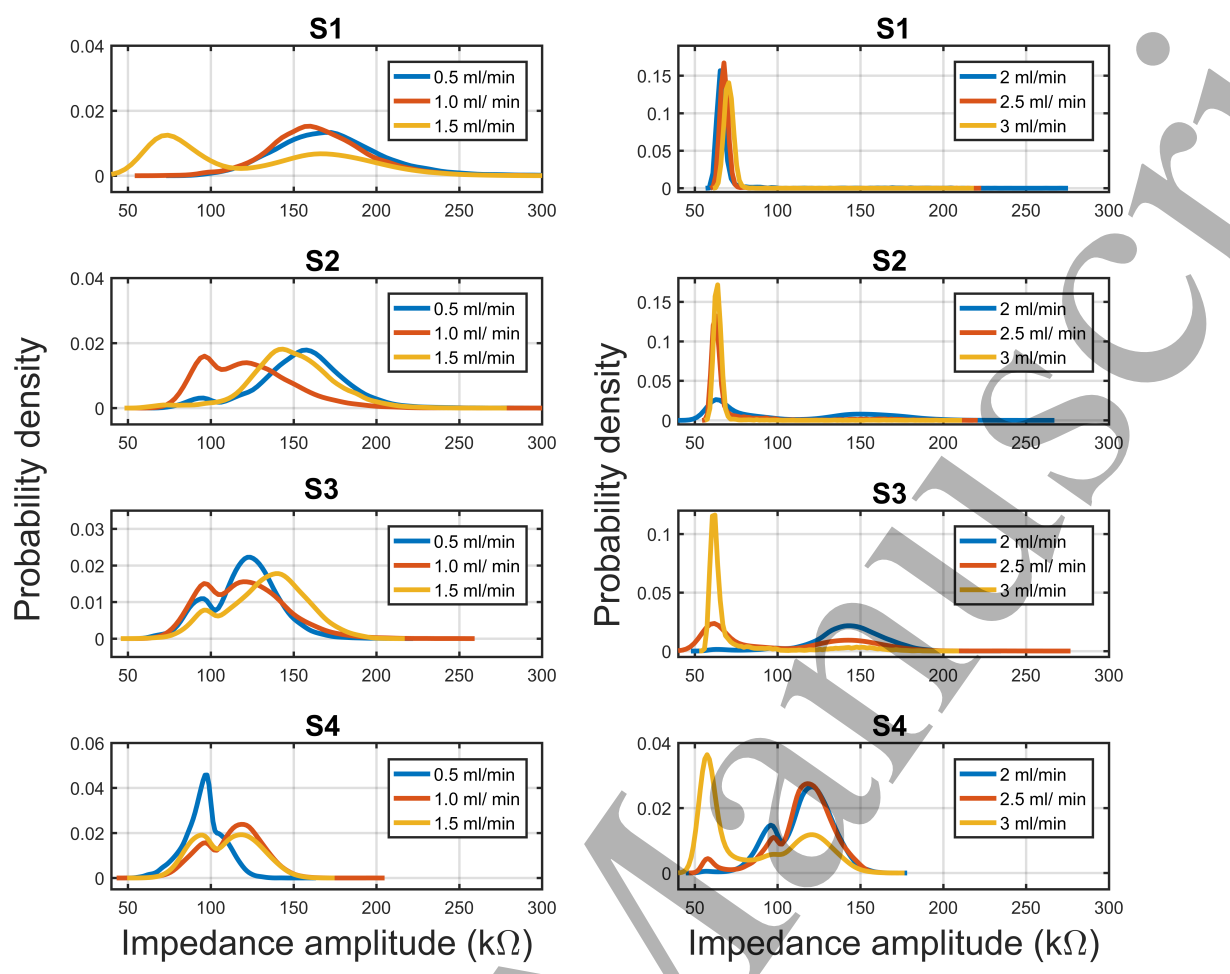

54

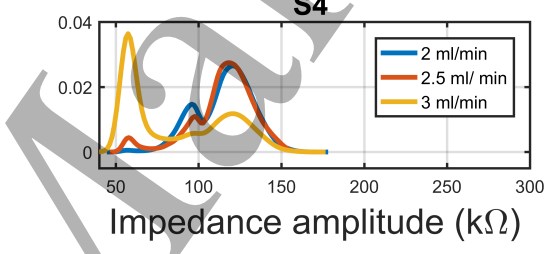

Figure 9. Probability density function and impedance amplitude measurements at 32.3 Watt for different flow regimes

condensation for a fast re-wetting process. Therefore, the peak of probability density decreases slightly (from $\sim 150 \mathrm{k} \Omega$ to $\sim 100 \mathrm{k} \Omega$ ) but stays in the vapor region from sensor 1 to sensor 4 .

\section{Discussions}

In this work, it has been shown that probability density function of the impedance measurement data at various locations along the microchannel has a direct correlation with two-phase flow regime inside the channel (see Figure 10). Impedance amplitudes and corresponding probability density curves were used as metrics to analyze boiling flow from a new perspective. This research was partially presented before [38] in constant temperature test conditions. To the best of authors knowledge, this investigation is the first time that electrical impedance sensors are implemented over boiling processes using de-ionized water as the application fluid in a metallic microchannel. The shapes of the probability density curves provide a path to detect and characterize the flow regime based on simple electrical measurements, as validated with recorded video. Four flow regimes were identified: bubbly, slug, slug/annular transition, and annular flow. When boiling is in the bubbly flow regime, a single peak in the proba-

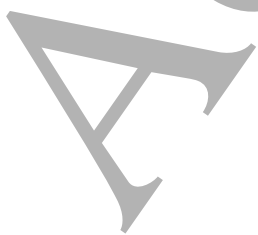


a.

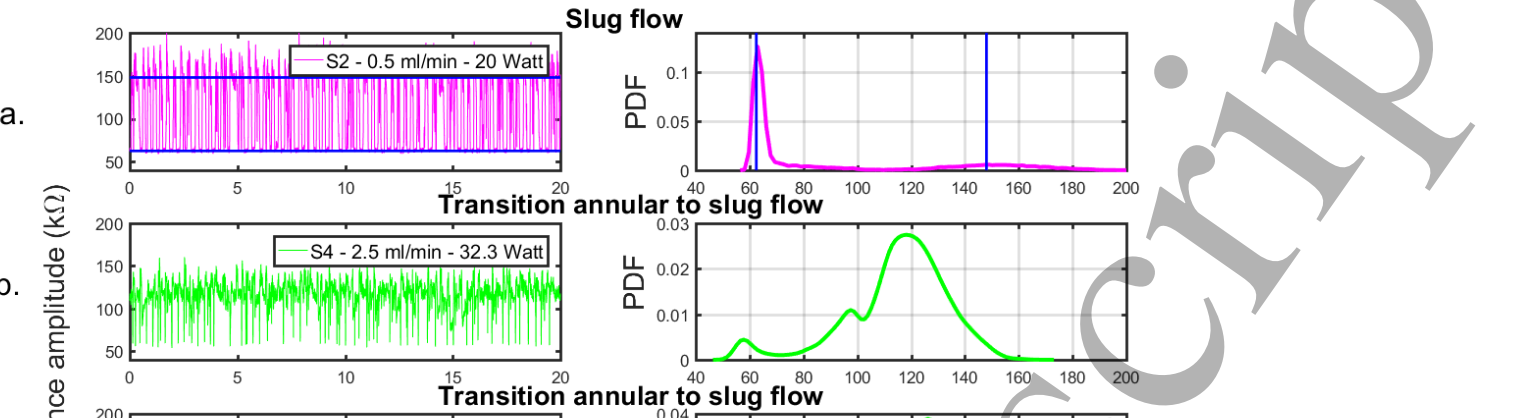

Slug flow

b.

c.
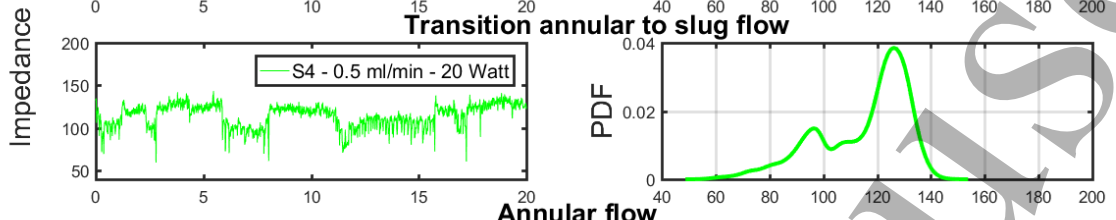

d.
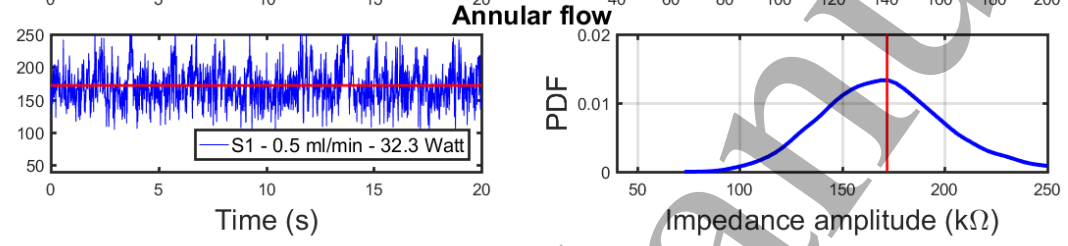

Figure 10. Correlation of probability density function curve shape and flow regime

bility density in the impedance $\sim 55 \mathrm{k} \Omega$ to $70 \mathrm{k} \Omega$ appears. In all slug flows, two peaks appear of which the first one represents passing water slugs and the second represents the vapor phase (see Figure 10 -a). Depending on the individual test, the vapor volume may differ significantly, resulting in a broader high impedance peak: $\sim 110 \mathrm{k} \Omega$ to $200 \mathrm{k} \Omega$ (see Figure 12). In the case of transition from slug to annular flow, the PDF curves corresponding to the transition flow regime present three peaks or an broader low impedance peak (see Figure 10 -b and -c).

For bubbly and annular flow, these respective peaks in the PDFs representing liquid and vapor phases respectively were analyzed by normal Gaussian fitting, and the mean values are exported. As for the characterization of slug flow, the statelevels function in Matlab was used.) The function bins data into a histogram with 100 bars and divides the data into two sub-histograms. Then the state levels are estimated by calculating the mean of the lower and upper histograms. An example of detected state levels in slug flow is shown in Figure 10-a. These mean values are considered representative of the liquid and vapor phases that repeatedly pass the sensor area. The vapor phase is surrounded by a thin layer of liquid on the channel walls. Figure 12 shows the whisker box plot of the exported mean values from sorted experimental results, in which the box represents the 25 to 75 percent of the data and the line shows the full range. The vapor phase corresponding to slug flow lies in a higher impedance range compared to the annular flow peak range. This can be either due to the fact that slugs are explosively expanding and the channel experiences a sudden dry out while in annular flow, a constant thin layer of liquid remains around the vapor core. Therefore, the liquid makes the media more conductive and decreases the impedance amplitude

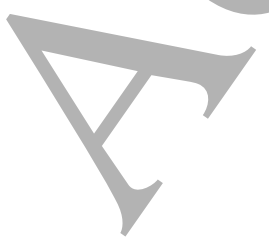


Table 2. Values of the coefficients for accuracy calculation [41].

on average. All in all, the distinct range of the impedance amplitude of liquid, bubble and vapor phase provides the opportunity to detect the boiling flow regime in the channel. This can potentially be used as a feedback in a cooling system or a phase monitoring system, especially in cases where thermal noises are reduced or well-known.

According to the datasheet of LCR meter provided by manufacturer, the device measurement accuracy of measured impedance amplitude $\left(Z_{x}\right)$ can be calculated by the Equation (1) and Equation (2) (constant values shown in Table 2):

\begin{tabular}{lll}
\hline Coefficient & Name & Value \\
\hline \multirow{2}{*}{ A } & basic accuracy $(10 k \Omega<$ Range $<100 k \Omega)$ & 0.25 \\
& basic accuracy $(100 k \Omega<$ Range $<1 M \Omega)$ & 0.5 \\
\hline
\end{tabular}

B basic accuracy $(10 k \omega<$ Range $<100 k \Omega) \quad 0.04$

B basic accuracy $(100 k \omega<$ Range $<1 M \Omega)$

\begin{tabular}{llll}
\hline $\mathrm{C}$ & level coefficient & 1.4 \\
\hline
\end{tabular}

D speed coefficient 8

E cable length coefficient 1.5

\begin{tabular}{lll}
\hline $\mathrm{F}$ & DC bias coefficient & 1 \\
\hline $\mathrm{G}$ & operating temperature coefficient & 1
\end{tabular}

G operating temperature coefficient 1

Measurement accuracy $=$ Basic accuracy $\times G \times D \times E \times F \times G$ [41]

Basic accuracy $= \pm\left(A+B \times\left|\frac{10 \times Z_{x}}{\text { Range }}-1\right|\right)[41]$

by applying these the impedance measurement uncertainty for each sensor is calculated as follow:

$$
\begin{aligned}
& 8.3 \%<\left|Z_{S 1}\right|_{\text {accuracy }}<10.1 \% \\
& 8.1 \%<\left|Z_{S 2}\right|_{\text {aceuracy }}<9.7 \% \\
& 8.4 \%<\left|Z_{S 3}\right|_{\text {accuracy }}<13.4 \% \\
& 7.77 \%<\left|Z_{S 4}\right|_{\text {accuracy }}<12.2 \%
\end{aligned}
$$

An example of uncertainty of the impedance measurement is shown in Figure 11. In order to examine the influence of uncertainties of the measured impedance over PDF curves, a noise over the main measured valued is using a random function in MATLAB produced in the uncertainty window. The probability density of the noisy data is calculated with the same method as presented in the manuscript. The box plot of the noisy data is shown in Figure 12 and compared with presented data in manuscript. Figure 12 represents that the applied random noise in the uncertainty window has minor influence on the final analysis. The reason for this phenomena is that the bin sizes that are used in making the probability density curves are similar or bigger than data error. Therefore, the current uncertainty will make little influence

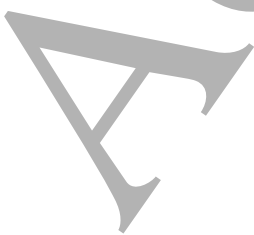


on the final result and shape of the PDF function in our analysis.

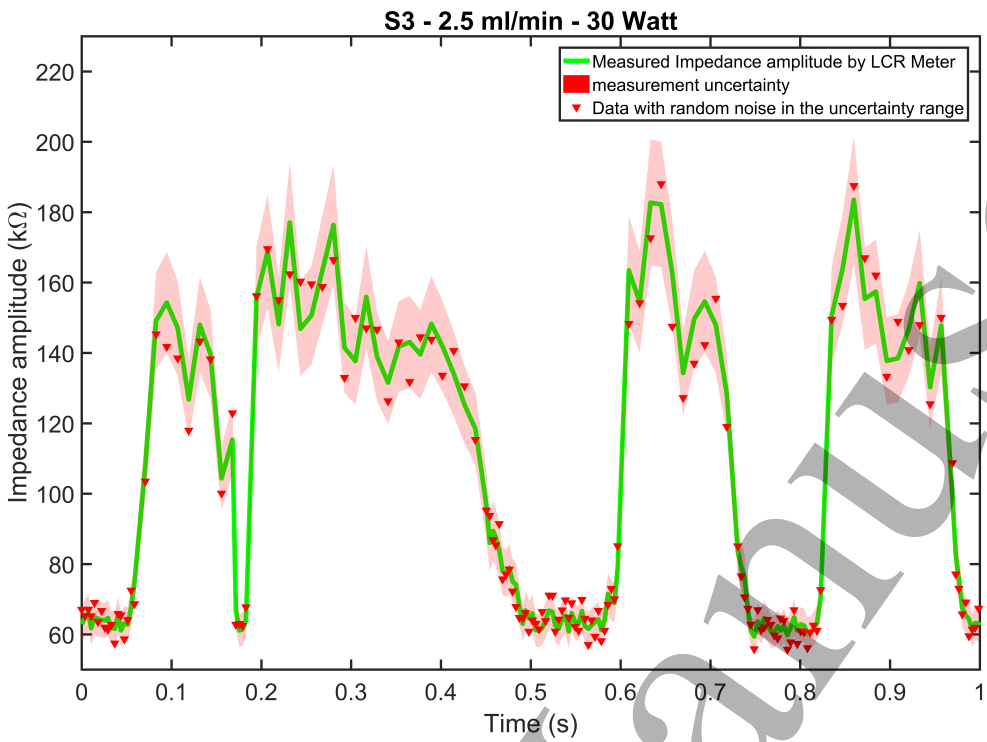

Figure 11. Example of the measured impedance and error range.

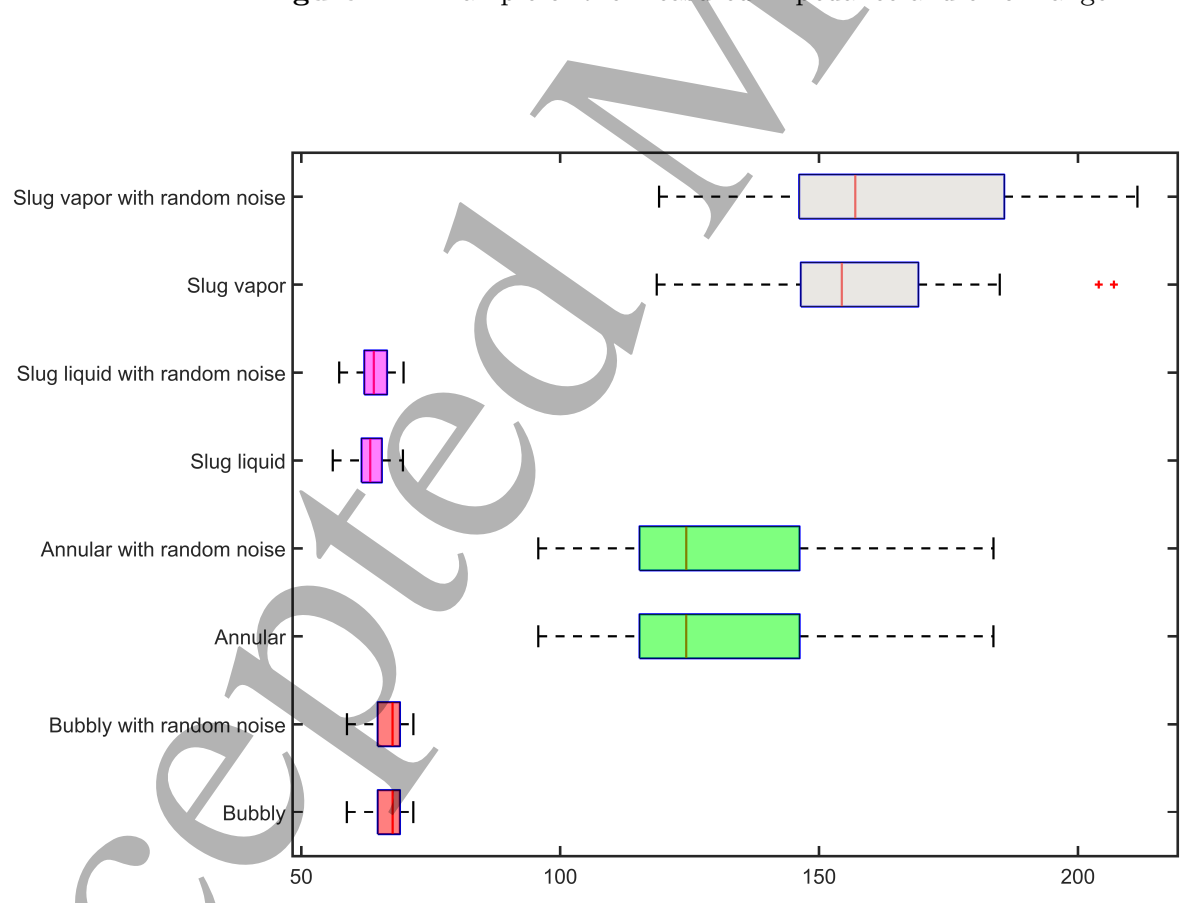

Figure 12. Whisker plot of the peak value of different phases based on probability density. 
The experimental method can be further extended in order to correlate the local heat transfer coefficient during boiling with impedemetric measurements. With larger datasets, including data from different electrode sizes for experiment condition, it is possible to train a neural network systems that classify a measurement signal in a flow regime category [45]. Regarding the limitations of this method following points most be considered. First, in our case, width of electrodes is slightly $(200 \mu \mathrm{m})$ bigger than channel width $(1.5 \mathrm{~mm})$. Applying the same method for a much smaller channel width under range of approximately $500 \mu \mathrm{m}$ will become more challenging due to dominance of noises. With the current setup, the other limitation is high flow rate boiling. In high flow rate boiling, the vapor bubbles or slugs will pass very quickly under the sensing area. Detection of fast moving bubbles with our sampling rate is not possible, however, a higher sampling rate measurement system can overcome this problem. Instead of individual bubble detection, we rely upon data averaged over the possible sampling period. One goal in the analysis of the PDF shape is to see if we can nevertheless differentiate between flow regimes without having to uniquely identify individual bubbles or slugs. This is an approach we introduce here which will require additional careful study. Third limitation is usage of this measurement analysis system in unstable temperature conditions that is not functioning in steady state condition. In these conditions, temperature oscillations will influence sensor read out. To avoid this, an extra calibration based on temperature is necessary, which will be challenging and non-trivial for mixtures of phases.

A lot of boiling heat transfer models, both physics based and empirical, try to predict heat transfer coefficient based on boundary condition and flow regime. Therefore, having more precise knowledge about flow regime in different locations of the boiling channel can be potentially used as both a feed-in to refine post-processing of heat transfer studies and feedback for control systems. Using multiple electrodes simultaneously working along the channel is potentially helpful for system control. Considering the $95 \%$ electric field envelope as limitation for design, the minimum pitch distance should be bigger than length of the electrode to avoid electrodes signal interference [29]. In case of electrode geometry, the electrode coverage does not have to be continuous along the whole length of the channel, however, having multiple electrodes can help to interpolate what happens between two different points in the channel. This would then still be âs inexpensive to implement as a single electrode at a single location, and would still be a manageable data handling situation comparing to highspeed videography or PIV methods. Due to the fact that most of the research on boiling flow is in the direction of heat transfer and thermodynamics, video recording is used as the reference for flow regime (ground truth) and physical parameters like temperature or pressure drop are recorded in parallel. This leads to having the video recording in only one single point of the channel while flow regime develops and may vary along the channel length. Therefore, here we present the integration of sensors based on electrical impedańce measurements as a contribution to the effort to in developing alternative and low-cost microchannel monitoring in two-phase flows. The sensors give information about fluid phase distributions inside the microchannel via the time-varying net electrical conductivity and electrical permittivity of the material in the sensing volume. 


\section{Acknowledgments}

Financial support by the German Research Foundation (DFG) through the Research Unit FOR 2383 ProMiSe under Grant No. Di 696/13-1 is gratefully acknowledged. The authors would like to thank Mr. Franz Richard, Mr. Heinz Lambach and the IMTEK cleanroom staff for their help with fabrication. In addition, authors would like to thank Ms. Angelina Müller and Dr. Andreas Weltin for their help on ITO wet etching processes and Mr. Manfred Kraut for scientific support.

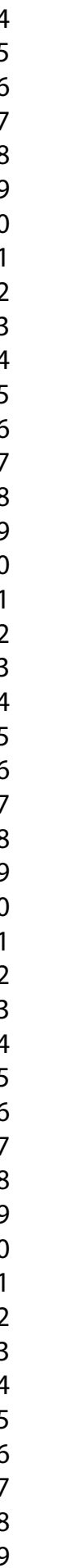

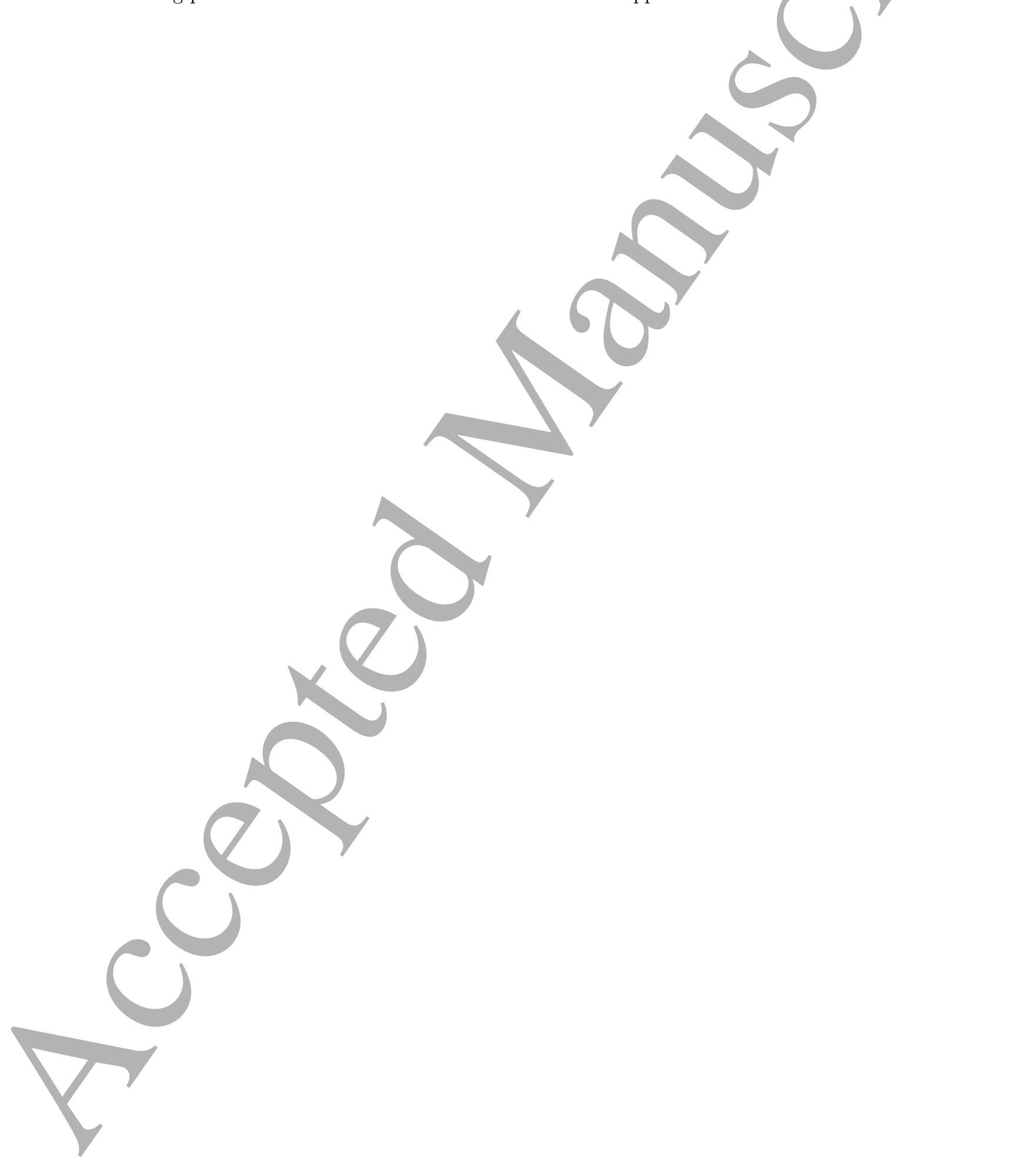




\section{References}

[1] T.G. Karayiannis and M.M. Mahmoud. Flow boiling in microchannels: Fundamentals and applications. Applied Thermal Engineering, 115:1372 1397, 2017. ISSN 1359-4311. doi: https://doi.org/10.1016/j.applthermaleng. 2016.08.063. URL http://www.sciencedirect.com/science/article/pii/ S1359431116314090.

[2] Issam Mudawar. Two-phase microchannel heat sinks: theory, applications, and limitations. Journal of electronic packaging, 133(4):041002, 2011.

[3] Abdolreza Fazeli and Saeed Moghaddam. A new paradigm for understanding and enhancing the critical heat flux (chf) limit. Scientific reports, 7(1):5184, 2017.

[4] Satish G Kandlikar. Fundamental issues related to flow boiling in minichannels and microchannels. Experimental Thermal and Fluid Science, 26(2):389 - 407, 2002. ISSN 0894-1777. doi: https://doi.org/10. 1016/S0894-1777(02)00150-4. URL http://www. sciencedirect.com/science/ article/pii/S0894177702001504.

[5] John R. Thome. State-of-the-art overview of boiling and two-phase flows in microchannels. Heat Transfer Engineering, 27(9):4-19, 2006. doi: 10.1080/ 01457630600845481 . URL https://doi.org/10.1080/01457630600845481.

[6] Satish G. Kandlikar. Chapter 5 - Flow bơiling in minichannels and microchannels. Elsevier Science Ltd, Oxford, 2006. ISBN 978-0-08-044527-4. doi: https:// doi.org/10.1016/B978-008044527-4/50007-4. URL http://www . sciencedirect. $\mathrm{com} / \mathrm{science/article/pii/B9780080445274500074.}$

[7] Satish G. Kandlikar. History, advances, and challenges in liquid flow and flow boiling heat transfer in microchannels: A critical review. Journal of Heat Transfer, 134, mar 2012. doi: doi:10.1115/1.4005126.

[8] D. Vijay K. S. Kandlikar, S. Masahiro. Handbook of phase change : boiling and condensation. Philadelphia (Pa.) : Taylor and Francis, 1999.

[9] Lixin Cheng, Gherhardt Ribatski, and John R Thome. Two-phase flow patterns and flow-pattern maps: fundamentals and applications. Applied Mechanics Reviews, 61(5):050802, 2008. doi: doi:10.1115/1. 2955990. URL https://appliedmechanicsreviews asmedigitalcollection. asme .org/article.aspx?articleid=1399061.

[10] Mrinal Jagirdar and Poh Seng Lee. A diagnostic tool for detection of flowregimes in a microchannel using transient wall temperature signal. Applied Energy, 185:2232 - 2244, 2017. ISSN 0306-2619. doi: https://doi.org/10. 1016/j.apenergy.2015.12.111. URL http://www.sciencedirect.com/science/ article/pii/S0306261915016840. Clean, Efficient and Affordable Energy for a Sustainable Future.

[11] W. L. Liu C. Tan and F. Dong. Characterizing the correlations between local phase fractions of gasliquid two-phase flow with wire-mesh sensor. Philosophical Transactions A, 374, 2016. doi: 10.1098/rsta.2015.0335. URL https:// royalsocietypublishing.org/doi/10.1098/rsta.2015.0335.

[12] Tannaz Harirchian and Suresh V. Garimella. A comprehensive flow regime map for microchannel flow boiling with quantitative transition criteria. International 


\section{REFERENCES}

Journal of Heat and Mass Transfer, 53(13):2694 - 2702, 2010. ISSN 00179310. doi: https://doi.org/10.1016/j.ijheatmasstransfer.2010.02.039. URL http: //www.sciencedirect.com/science/article/pii/S0017931010001158.

[13] Satish G. Kandlikar. Scale effects on flow boiling heat transfer in microchannels: A fundamental perspective. International Journal of Thermal Sciences, 49(7): 1073 - 1085, 2010. ISSN 1290-0729. doi: https://doi.org/10.1016/j.ijthermalsci. 2009.12.016. URL http://www.sciencedirect.com/science/article/pii/ S1290072910000098.

[14] Y. S Tian L. Chen and T.G Karayiannis. R134a flow patterns in small-diameter tubes. Journal of Process Mechanical Engineering, 219(2):167-181, may 2005. doi: 10.1243/095440805X7071. URL https://journals. sagepub.com/doi/pdf/10. 1243/095440805X7071.

[15] Tassos Karayiannis, Emily Pike-Wilson, Lejun Chen, Mohamed Mahmoud, and Yongsheng Tian. Flow patterns and comparison with correlations for vertical flow boiling of r245fa in small to micro tubes. 092014.

[16] Rémi Revellin, Vincent Dupont, Thierry Ursenbacher, John R. Thome, and Iztok Zun. Characterization of diabatic two-phase flows in microchannels: Flow parameter results for R-134a in a $0.5 \mathrm{~mm}$ channel. International Journal of Multiphase Flow, 32(7):755-774, 2006. ISSN 03019322. doi: 10.1016/j. ijmultiphaseflow.2006.02.016.

[17] Mohamed M. Mahmoud and Tassos G. Karayiannis. Flow pattern transition models and correlations for flow boiling in mini-tubes. Experimental Thermal and Fluid Science, 70:270 - 282, 2016. ISSN 0894-1777. doi: https://doi.org/10.1016/ j.expthermflusci.2015.09.023. URL http://www/sciencedirect.com/science/ article/pii/S089417771500268X.

[18] I. Hassan, M. Vaillancourt, and K. Pehlivan. Two-phase flow regime transitions in microchannels: A comparative experimental study. Microscale Thermophysical Engineering, 9(2):165-182, 2005. doi: 10.1080/10893950590945049. URL https: //doi.org/10.1080/10893950590945049.

[19] Tamanna Alam, Poh Seng Lee, and Christopher R. Yap. Effects of surface roughness on flow boiling in silicon microgap heat sinks. International Journal of Heat and Mass Transfer, 64:28 - 41, 2013. ISSN 0017-9310. doi: https://doi.org/ 10.1016/j.ijheatmasstransfer.2013.04.009. URL http://www.sciencedirect. com/science/article/pii/S0017931013003141.

[20] Satish G Kandlikar, Theodore Widger, Ankit Kalani, and Valentina Mejia. Enhanced flow boiling over open microchannels with uniform and tapered gap manifolds. Journal of Heat Transfer, 135(6):061401, 2013.

[21] Y. Mi, M. Ishii, and L.H. Tsoukalas. Vertical two-phase flow identification using advanced instrumentation and neural networks. Nuclear Engineering and Design, 184(2):409 - 420, 1998. ISSN 0029-5493. doi: https://doi. org/10.1016/S0029-5493(98)00212-X. URL http://www.sciencedirect.com/ science/article/pii/S002954939800212X.

[22] E S Rosa, B F Flora, and M A S F Souza. Design and performance prediction of an impedance void meter applied to the petroleum industry. Measurement Science and Technology, 23(5):055304, 2012. URL http://stacks . iop.org/0957-0233/ $23 / i=5 / a=055304$.

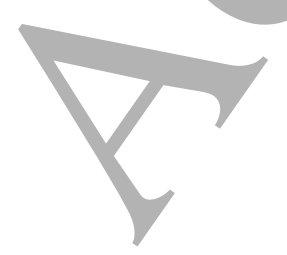


[23] E. N. Dos Santos, A. D. N. Wrasse, T. P. Vendruscolo, N. S. Reginaldo, G. Torelli, R. F. Alves, B. P. Naidek, R. E. M. Morales, and M. J. Da Silva. Sensing platform for two-phase flow studies. IEEE Access, 7:5374-5382, 2019. ISSN 2169-3536. doi: 10.1109/ACCESS.2018.2887309.

[24] Sidharth Paranjape, Susan N. Ritchey, and Suresh V. Garimella c. Electrical impedance-based void fraction measurement and flow regime identification in microchannel flows under adiabatic conditions. International Journal of Multiphase Flow, 42:175 - 183, 2012. ISSN 0301-9322. doi: https://doi.org/ 10.1016/j.ijmultiphaseflow.2012.02.010. URL http://www. sciencedirect.com/ science/article/pii/S0301932212000389.

[25] Mohammadmahdi Talebi, Keith Cobry, Ananya Sengupta, and Peter Woias. Transparent glass/su8-based microfluidic device with on-channel electrical sensors. Proceedings of Eurosensors 2017, Paris, France, 1(4), 2017. doi: 10.3390/proceedings1040336. URL http://www . mdpi . com/2504-3900/1/4/336.

[26] Mohammadmahdi Talebi, Peter Woias, and Keith Cobry. Analysis of impedance data from bubble flow in a glass/su8 microfluidic device with on-channel sensors. Sensors and Actuators A: Physical, 279:543 - 552,2018. ISSN 0924-4247. doi: https://doi.org/10.1016/j.sna.2018.07.004. URL http://ww. sciencedirect. com/science/article/pii/S0924424717319210.

[27] Pieter Gijsenbergh and Robert Puers. Permittivity-based void fraction sensing for microfluidics. Sensors and Actuators A: Physical, 195:64 - 70, 2013. ISSN 0924-4247. doi: https://doi.org/10.1016/j.sna.2013.02.019. URL http://www. sciencedirect.com/science/article/pii/s0924424713001064.

[28] M. S. Rocha and J. R. Simões-Moreira. Void Fraction Measurement and Signal Analysis from Multiple-Electrode Impedance Sensors. Heat Transfer Engineering, 29(11):924-935, 2008. ISSN 0145-7632. doi: 10.1080/01457630802186015. URL http://www. tandfonline.com/doi/abs/10 . 1080/01457630802186015.

[29] Pierre Valiorgue, Susan N Ritchey, Justin A Weibel, and Suresh V Garimella. Design of a non-intrusive electrical impedance-based void fraction sensor for microchannel two-phase flows. Measurement Science and Technology, 25(9): 095301, 2014. URL http://stacks.iop.org/0957-0233/25/i=9/a=095301.

[30] H. Ahmed. Capacitance sensors for void-fraction measurements and flow pattern identification. IEEE Sensors Journal, 6(5):1153-1163, Oct 2006. ISSN 1530-437X. doi: 10.1109/JSEN.2006.881390.

[31] Wael H Ahmed and Basel I Ismail. Innovative techniques for two-phase flow measurements. Recent Patents on Electrical \&3 Electronic Engineering (Formerly Recent Patents on Electrical Engineering), 1(1):1-13, 2008. doi: 10.2174/ 1874476110801010001.

[32] M. Fossa. Design and performance of a conductance probe for measuring the liquid fraction in two-phase gas-liquid flows. Flow Measurement and Instrumentation, 9(2):103 - 109, 1998. ISSN 0955-5986. doi: https://doi.org/10. 1016/S0955-5986(98)00011-9. URL http://www. sciencedirect.com/science/ article/pii/s0955598698000119.

[33] Nikolas Libert, Rigoberto E.M. Morales, and Marco Jose da Silva. Capacitive measuring system for two-phase flow monitoring. part 1: Hardware design and evaluation. Flow Measurement and Instrumentation, 47:90 - 99, 2016. ISSN 
0955-5986. doi: https://doi.org/10.1016/j.flowmeasinst.2015.12.009. URL http: //www.sciencedirect.com/science/article/pii/S0955598615300480.

[34] Nikolas Libert, Rigoberto E.M. Morales, and Marco Jose da Silva. Capacitive measuring system for two-phase flow monitoring. part 2: Simulation-based calibration. Flow Measurement and Instrumentation, 50:102 - 111, 2016. ISSN 0955-5986. doi: https://doi.org/10.1016/j.flowmeasinst.2016.05.011. URL http: //www.sciencedirect.com/science/article/pii/S0955598616300425.

[35] Ji Janou, Ji ech, Pavel Bernek, Michal Pibyl, and Dalimil nita. Ac electric sensing of slug-flow properties with exposed gold microelectrodes. Journal of Micromechanics and Microengineering, 24(1):015002, 2014. URL http:// stacks.iop.org/0960-1317/24/i=1/a=015002.

[36] Petr Polezhaev, Zdenk Slouka, Ji Lindner, and Michal Pibyl. Characterization of slug flow of two aqueous phases by electrochemical impedance spectroscopy in a fluidic chip. Microelectronic Engineering, 194:89 - 95, 2018. ISSN 0167-9317. doi: https://doi.org/10.1016/j.mee.2018.03.003. URL http://www.sciencedirect. com/science/article/pii/S0167931718301138.

[37] M. Talebi, K. Cobry, Z. Zhou, S. Sadir, R. Dittmeyer, and P. Wøias. Investigation of boiling phenomena in microchannels using impedance spectroscopy technique correlated with videography. In MikroSystem Technik Congress, pages 1-4. VDE, Oct 2017.

[38] Mohammadmahdi Talebi, Keith Cobry, Sahba Sadir, Roland Dittmeyer, and Peter Woias. Flow regime detection of boiling flow in microchannels using electrical sensing elements validated by videography. In ASME 2018 16th International Conference on Nanochannels, Microchannels, and Minichannels, page V001T02A016. American Society of Mechanical Engineers, 2018.

[39] Prasanna Jayaramu, Sateesh Gedupudi, and Sarit K. Das. Influence of heating surface characteristics on flow boiling in a copper microchannel: Experimental investigation and assessment of correlations. International Journal of Heat and Mass Transfer, 128:290 - 318, 2019. ISSN 0017-9310. doi: https://doi.org/10. 1016/j.ijheatmasstransfer.2018.08.075. URL http://www.sciencedirect.com/ science/article/pii/S0017931018312833.

[40] Benjamin J Jones and Suresh V Garimella. Surface roughness effects on flow boiling in microchannels. Journal of Thermal Science and Engineering Applications, 1(4):041007, 2009.

[41] HIOKI IM3536 LCR METER Instruction Manual, 2nd edition, sep 2016. URL https://www.hioki.com.

[42] Pico Technology USB TC-08-channel thermocouple data logger data sheet, 9th edition, apr 2019. URL https://www.picotech.com/download/datasheets/ lusb-tc-08-thermocouple-data-logger-data-sheet.pdf.

[43] Product information mzr-7205 High performance pump series, jul 2019. URL https://www hnp-mikrosysteme.de/uploads/media/pdfs/mzr-7205_0 .pdf.

[44] Owen C. Jones and Novak Zuber. The interrelation between void fraction fluctuations and flow patterns in two-phase flow. International Journal of Multiphase Flow, 2(3):273 - 306, 1975. ISSN 0301-9322. doi: https://doi.org/10. 1016/0301-9322(75)90015-4. URL http://www.sciencedirect.com/science/ article/pii/0301932275900154. 
[45] Abdeel J. Roman, Paul J. Kreitzer, Jamie S. Ervin, Michael S. Hanchak, and Larry W. Byrd. Flow pattern identification of horizontal two-phase refrigerant flow using neural networks. International Communications in Heat and Mass Transfer, 71:254 - 264, 2016. ISSN 0735-1933. doi: https://doi.org/10. 1016/j.icheatmasstransfer.2015.12.033. URL http://www.sciencedirect.com/ science/article/pii/S073519331500281X. 